\title{
Three LIF-dependent signatures and gene clusters with atypical expression profiles, identified by transcriptome studies in mouse ES cells and early derivatives
}

\author{
Marina Trouillas ${ }^{1,2,3}$, Claire Saucourt ${ }^{1,2}$, Bertrand Guillotin ${ }^{1,2}$, \\ Xavier Gauthereau ${ }^{1,2}$, Li Ding ${ }^{4}$, Frank Buchholz ${ }^{4}$, Michael Xavier Doss ${ }^{5}$, \\ Agapios Sachinidis ${ }^{5}$, Jurgen Hescheler ${ }^{5}$, Oliver Hummel ${ }^{6}$, Norbert Huebner ${ }^{6}$, \\ Raivo Kolde 7 , Jaak Vilo 7 , Herbert Schulz ${ }^{6}$ and Hélène Bøeuf*1,2
}

Address: ${ }^{1}$ Université Bordeaux, Bordeaux, France, ${ }^{2}$ CNRS-UMR-5164-CIRID, Bordeaux, France, ${ }^{3}$ CTSA, Département Recherches et Thérapies Cellulaires, Clamart, France, ${ }^{4}$ MPI-CBG, Pfotenhauer Str. 108, 01307 Dresden, Germany, ${ }^{5}$ Center of physiology and Pathophysiology, Institute of Neurophysiology and Center of Molecular Medecine, University of Cologne (CMMC), Robert Koch Strasse 39, 50931 Cologne, Germany, ${ }^{6} \mathrm{Max}-$ Delbrück Center for Molecular Medecine, MDC Berlin, Buch Robert Roessle, Strasse 10, D13125- Berlin, Germany and ${ }^{7}$ Institute of Computer Science, University of Tartu, Liivi 2, 50409 Tartu, Estonia and Quretec Ltd, Ulikooli 6a, Tartu, Estonia

Email: Marina Trouillas - marina.trouillas@hotmail.com; Claire Saucourt - claire.saucourt@gmail.com;

Bertrand Guillotin - bertrand.guillotin@inserm.fr; Xavier Gauthereau - xavier.gauthereau@u-bordeaux2.fr; Li Ding - ding@mpi-cbg.de; Frank Buchholz - buchholz@mpi-cbg.de; Michael Xavier Doss - mxj2001@med.cornell.edu; Agapios Sachinidis - a.sachinidis@uni-koeln.de; Jurgen Hescheler - j.hescheler@uni-koeln.de; Oliver Hummel - o.hummel@mdc-berlin.de; Norbert Huebner - nhuebner@mdc-berlin.de; Raivo Kolde - rkolde@gmail.com; Jaak Vilo - vilo@ut.ee; Herbert Schulz - heschulz@mdc-berlin.de; Hélène Bøuf* - helene.boeuf@ubordeaux $2 . \mathrm{fr}$

* Corresponding author

Published: 9 February 2009

BMC Genomics 2009, 10:73 doi:10.1186/147|-2164-10-73
Received: 17 September 2008

Accepted: 9 February 2009

This article is available from: http://www.biomedcentral.com/147/-2164/10/73

(C) 2009 Trouillas et al; licensee BioMed Central Ltd.

This is an Open Access article distributed under the terms of the Creative Commons Attribution License (http://creativecommons.org/licenses/by/2.0), which permits unrestricted use, distribution, and reproduction in any medium, provided the original work is properly cited.

\begin{abstract}
Background: Mouse embryonic stem (ES) cells remain pluripotent in vitro when grown in the presence of the cytokine Leukaemia Inhibitory Factor (LIF). Identification of LIF targets and of genes regulating the transition between pluripotent and early differentiated cells is a critical step for understanding the control of ES cell pluripotency.

Results: By gene profiling studies carried out with mRNAs from ES cells and their early derivatives treated or not with LIF, we have identified i) LIF-dependent genes, highly expressed in pluripotent cells, whose expression level decreases sharply upon LIF withdrawal [Pluri genes], ii) LIF induced genes [Lifind genes] whose expression is differentially regulated depending upon cell context and iii) genes specific to the reversible or irreversible committed states. In addition, by hierarchical gene clustering, we have identified, among eight independent gene clusters, two atypical groups of genes, whose expression level was highly modulated in committed cells only. Computer based analyses led to the characterization of different sub-types of Pluri and Lifind genes, and revealed their differential modulation by Oct4 or Nanog master genes. Individual knock down of a selection of Pluri and Lifind genes leads to weak changes in the expression of early differentiation markers, in cell growth conditions in which these master genes are still expressed.
\end{abstract}

Conclusion: We have identified different sets of LIF-regulated genes depending upon the cell state (reversible or irreversible commitment), which allowed us to present a novel global view of LIF 
responses. We are also reporting on the identification of genes whose expression is strictly regulated during the commitment step. Furthermore, our studies identify sub-networks of genes with a restricted expression in pluripotent ES cells, whose down regulation occurs while the master knot (composed of OCT4, SOX2 and NANOG) is still expressed and which might be downregulated together for driving cells towards differentiation.

\section{Background}

Mouse embryonic stem cells (ES), which are derived from the inner cell mass of blastocysts, are valuable for studying pluripotency. Indeed, these cells recapitulate the complete mouse developmental program when injected into fertilized eggs and are widely used to introduce targeted mutations in mice $[1,2]$. In addition, they can be induced to differentiate in vitro to various cell types of the three germ layers and are therefore of great interest for study signalling pathways leading to specialized cell differentiation [3-5]. Knowledge of molecular determinants that regulate stem cell fate and understanding their functions are key challenges for future therapy based on stem cells in which their plasticity has to be properly controlled.

Two major pathways have been characterized so far, leading to the identification of "master genes" critical for the maintenance of mouse ES cell pluripotency: the LIF/ STAT3 pathway, which synergizes with BMP2/4 and/or Wnt family members (as Wnt3a, Wnt5a and Wnt6, [6-8]), to maintain ES cell pluripotency alone [9-14], and the OCT4/SOX2 and NANOG pathways, the last one identified in cells in which the LIF pathway has been knockeddown [15-20]. The many known regulators of ES cell pluripotency, like $c$-yes, [21],c-myc, [22], foxd3 [20] and those characterized by gene profiling studies [23-26] might be classified in one or the other pathway. However, the exhaustive characterisation of transcriptional targets of LIF in ES cells and in their early differentiated derivatives has not been reported and the specificity of LIF targets versus those of OCT4 or NANOG has not yet been investigated [27-29].

LIF is a member of the Interleukin-6 (IL-6) family of cytokines, which displays pleiotropic functions, depending on both cell maturity and cell type [30-32]. Indeed, while LIF maintains ES cell pluripotency and is a critical cell survival factor in myocytes, embryonic germ cells, particular subtypes of neurons and osteoblasts, it induces differentiation of the M1 leukemic myeloid cell line, can switch the identity of neurons [33], induces cell cycle arrest in cancer cells [34] and has a key pro-apoptotic role during the post-gestation process of mammary gland involution [35-37].

In mouse ES cells, LIF induces signalling pathways including JAK1/STAT3/MYC/CD9/SOCS3/PI3K and ERK/RSK/
CREB leading to activation of both anti- and pro-differentiative signals [23,38-44]. The transcriptional targets of LIF are the outcomes of these signalling cascades and their identification is a critical step for understanding the control of ES cell pluripotency. Also, LIF-dependent gene profiling performed in various cell states (pluripotent, reversible and irreversible commitment), should help to define different groups of LIF responsive genes, leading to a better understanding of pleiotropic effects of this cytokine.

The aim of this study was to characterize the LIF transcriptome of mouse ES cells as well as to identify novel regulators of the transition from pluripotent to irreversibly committed cells. By gene profiling studies, performed on ES cells cultured under various conditions, we have identified eight independent gene clusters including a novel gene category whose expression level varies transiently in reversibly committed cells only. Moreover, our strategy allowed us to identify different sets of LIF-regulated genes and to define those ones also regulated by OCT4 or NANOG. The effects of selected genes on ES cell differentiation were also investigated.

\section{Results}

\section{I) - LIF targets in mouse ES cells: experimental design}

To identify LIF targets in pluripotent and committedderived ES cells as well as key genes regulated during the transition from pluripotent to early differentiated cells, we carried out an experimental strategy based on these three facts i) A complete change of cell culture medium (including serum and LIF) is required every $48 \mathrm{~h}$ to induce a boost in STAT3 phosphorylation allowing cells to remain pluripotent, ii) $24 \mathrm{~h}$ after LIF withdrawal, STAT3 is inactivated by dephosphorylation and if incubated for longer in the absence of LIF, ES cells will differentiate. However, if LIF is added back $24 \mathrm{~h}$ after its withdrawal, differentiation is prevented and cells maintain their pluripotent state. Cells generated following 24 h of LIF starvation can therefore be categorised as in a state of reversible commitment, iii) $48 \mathrm{~h}$ following LIF withdrawal, while remaining LIFsensitive, cells are irreversibly committed to differentiate. Indeed, even if LIF is added back, cells differentiate and a proportion of them die by apoptosis [24,38,45-47]. The LIF-dependent kinetic experiments of STAT3 activation showed a maximal stimulation at $30 \mathrm{~min} .$, which corresponds to the maximal level of phospho-tyr705 and phos- 


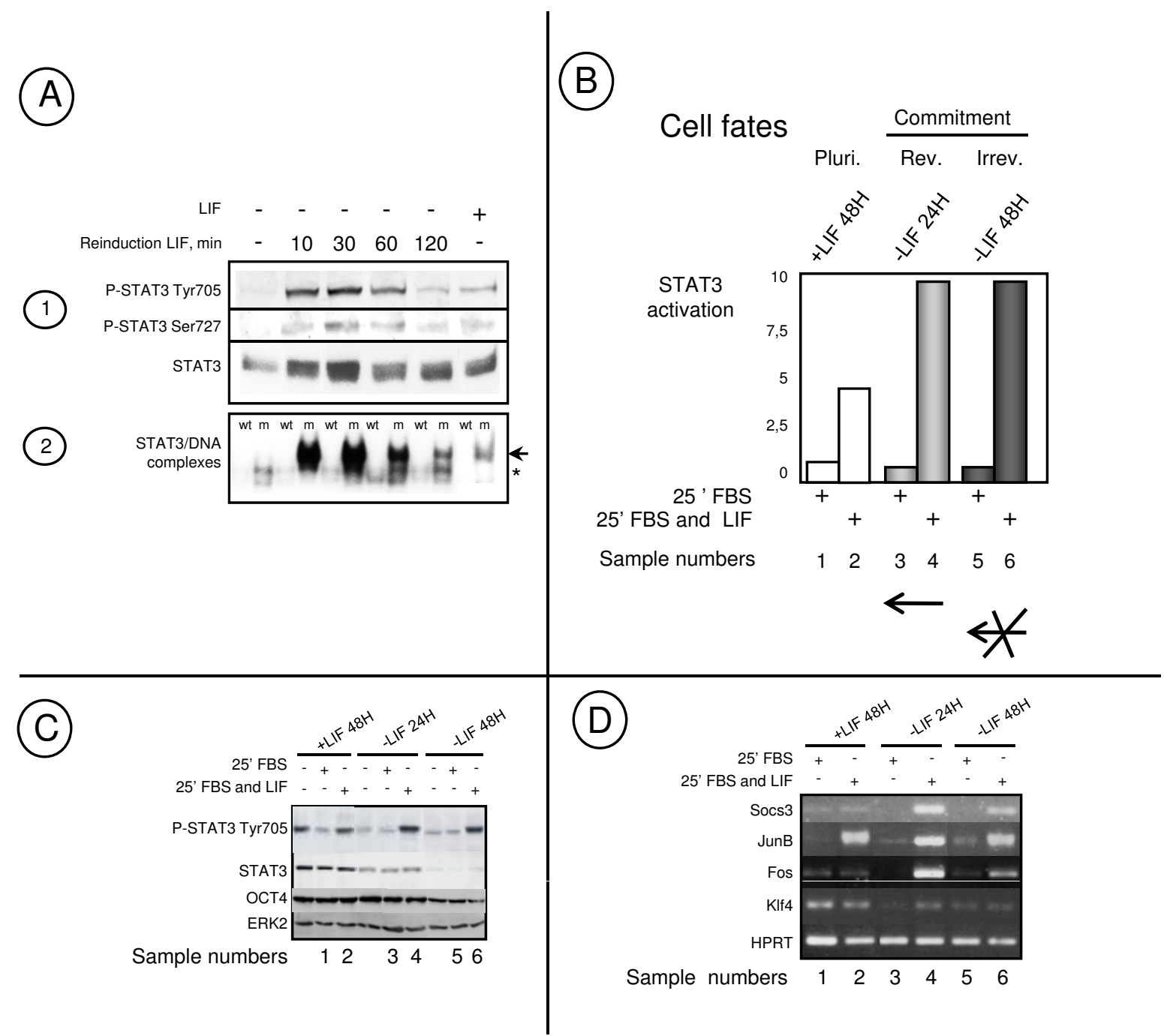

\section{Figure I}

The experimental strategy. A1) Western blot analyses showing STAT3 and P-STAT3 and A2) band shift analyses of specific LIF-dependent complexes in ES cells depleted of LIF for $24 \mathrm{~h}$ and reinduced with LIF for 10 to 120 min. or in pluripotent cells (+ LIF) as indicated. LIF specific complexe containing STAT3 (arrow) and non specific complexe (asterisk) are indicated. B) Diagram summarising the cell growth conditions used for microarray experiments: Mouse ES cells, in the pluripotent state (grown with LIF for $48 \mathrm{~h}$, Pluri.) or induced to differentiate by LIF withdrawal for $24 \mathrm{~h}$ [reversible commitment (Rev.)] or $48 \mathrm{~h}$ [irreversible commitment (Irrev.)], have been treated for $25 \mathrm{~min}$. with 10\% FBS or 10\% FBS and $500 \mathrm{pM} \mathrm{LIF} \mathrm{(+),} \mathrm{as} \mathrm{indicated,}$ before harvesting. Sample numbers correspond to the conditions compared in Tables I to 7 (see Additional file I). C) Quality controls of LIF response: Protein RIPA cell extracts from ES cells grown with LIF for $48 \mathrm{~h}$ or without LIF for 24 or $48 \mathrm{~h}$ and not treated (-) or treated for 25 min with FBS or FBS and LIF as in B). Western blot analysis were performed with antibodies reacting against all forms of STAT3 (STAT3), the activated STAT3 (P-STAT3 Tyr705) or with OCT4 and ERK2. D) Semi-quantitative RT-PCR performed with total RNAs from ES cells grown as indicated in B), have been performed with primers corresponding to the indicated genes. 
pho-ser727 STAT3 protein leading to the formation of active STAT3-DNA complexes (Figure 1A).

Gene profiling experiments were carried out with mRNA extracted from the CGR8 mouse ES cell line cultured under growth conditions as defined in Figure 1B. Cells in Pluripotent (Pluri), reversible (Rev.) or irreversible (Irrev.) commitment states were treated with serum or serum and LIF, $25 \mathrm{~min}$. before harvesting. Protein lysates were also prepared in parallel with RNA samples. Analysis of LIF-dependent induction of STAT3, as detected by the extent of its phosphorylation, confirmed LIF responsiveness of pluripotent, reversibly, and irreversibly committed cells. In addition, we observed a progressive decrease in the levels of STAT3 protein after $24 \mathrm{~h}$ and $48 \mathrm{~h}$ of LIF starvation, which correlates with the loss of cell pluripotency. In contrast, no changes in OCT4 protein level was observed at these early times of cell differentiation. As expected, the amount of ERK2 proteins was unaltered under these various conditions and therefore, it was used as a protein loading control (Figure 1C). The quality of mRNA hybridized to microarrays was checked by RT-PCR experiments on a control (Hprt) and known LIF-induced genes as Socs3, JunB and Fos and the pluripotent Klf4 gene, [23,48], (Figure 1D).

\section{2) Gene expression profiling in the absence or presence of LIF}

Five independent total RNA preparations from each condition, (Figure 1B), were processed and hybridized on the Mouse Genome 4302.0 Array (Affymetrix) which includes 45101 probe sets. After RMA normalisation [49] and outlier removal, pairwise comparisons have been performed using the paired Student t-test (summarized in Figure 2). This allows the classification of genes into 7 tables (Tables 1 to 7 , see Additional file 1). In addition, multiple testing correction has been performed using the Benjamini and Hochberg procedure [50,51], as described in the Methods section.

Tables 1 and 2 show the sets of the LIF-regulated genes detected in ES cells reversibly and irreversibly committed to differentiate following acute treatment with LIF. Genes whose expression was induced by LIF, named hereafter Lifind genes, belong to various gene families including the Early growth response genes $(E g r 1,2)$, members of Immediate early response (Ier2 and 3), and of Kruppel-related gene (Klf4 and 5) families, Ras-dex1, Ypel2 and the PI3K regulator Dapp1. In addition, an EST of unknown function, 1459961_at, encoded by a gene localized at proximity of the Stat3 locus ( $5^{\prime}$ to the promoter) has also been retrieved (named Stat3Loc, see Additional file 2). A subgroup of genes induced after $24 \mathrm{~h}$ of LIF withdrawal was also induced after a $48 \mathrm{~h}$ period of LIF starvation (compare Tables 1 and 2). In addition, few LIF-repressed genes
(Lifrep genes), with the extent of repression less than 2fold, were retrieved $24 \mathrm{~h}$ after LIF withdrawal (Ddh2, Mtss1, Chd8 and ESTs), and no repressed genes were identified after $48 \mathrm{~h}$ of LIF starvation. While our stringent criteria of gene selection by the t-test analyses do not lead to the identification of LIF-modulated genes in pluripotent cells (+ LIF conditions), we detected a LIF-dependent increased expression of some genes, including Ypel2, Plscr1, Dapp1, JunB, Stat3Loc and Klf5, in pluripotent cells, by semi-quantitative RT-PCR analysis (see below, Figure 4). Altogether, these results showed that the LIF response was different in pluripotent, reversibly and irreversibly committed cell populations, suggesting that LIF outcomes do not rely on the sole activation of STAT3, similarily induced in these three conditions.

Tables 3 and 4 depict pair-wise comparisons of genes whose expression was significantly diminished after $24 \mathrm{~h}$ (Table 3 ) or $48 \mathrm{~h}$ of LIF starvation (Table 4 ) in comparison to pluripotent cells (+LIF conditions). In this analysis, Lifind genes, as defined in Table 1, were also retrieved (as Socs3, Junb and Klf4) indicating that some cell fate-regulated genes could also be reinducible by LIF, a property not shared by the majority of genes retrieved in these Tables. This analysis allowed to identify the core "Pluri" genes including known pluripotent markers such as Stat3, Nanog, Klf4, Yes, Zfp42/rex1, Bcl3, Spp1, Cd9, Esrrb, Tbx3, Tcl1 [25,47] and members of gene families not yet described to be regulated in the ES cell model. We identified genes encoding for proteins involved in cell adhesion (as Ceacam1 and 2), Wnt (Fzd5, Mitf, Aes), Ras (Mras, Ulk1), Notch (Notch4), Interleukin1 (Irak3) and Tgfb $(B m p 4, I n h b b)$ signalling pathways, in cytoskeleton organization (Mapt/Tau, Myosin IF, Pdgfa), and in lipid (Abca1, Cpt1a) and superoxide anion metabolism (Sod2). Many transcription factors (Tcfcp2like1, Trps1, Sox21, Arid5b, NrOb1, Zfp57, Musculin) and chromatin regulators (Myst4) were also identified.

Tables 5, 6 and 7 gather genes whose expression increases upon LIF withdrawal. Twenty genes, whose expression level was up regulated in irreversibly committed cells versus pluripotent cells, were also expressed in reversibly committed cells (genes quoted as "YES" in Table 5, like Lef1, Wt1, Dnmt3a and b, Oct6 and Otx2). This findings suggest that irreversible commitment maybe linked to the sustained expression of a set of genes expressed at earlier time following LIF withdrawal. In table 5, we noted that the majority of genes (120 out of 140 ) has a particular expression profile characterized by low level of expression in pluripotent cells, high level of expression in reversibly committed cells and low level of expression again in irreversibly committed cells ("low-high-low" profile, quoted as "NO", in Table 5). These genes, including Bhc80, Bicd1, Six4, Bmi1, Aire, Jmjd1c, Jmjd2c and Tle4, define a new cat- 


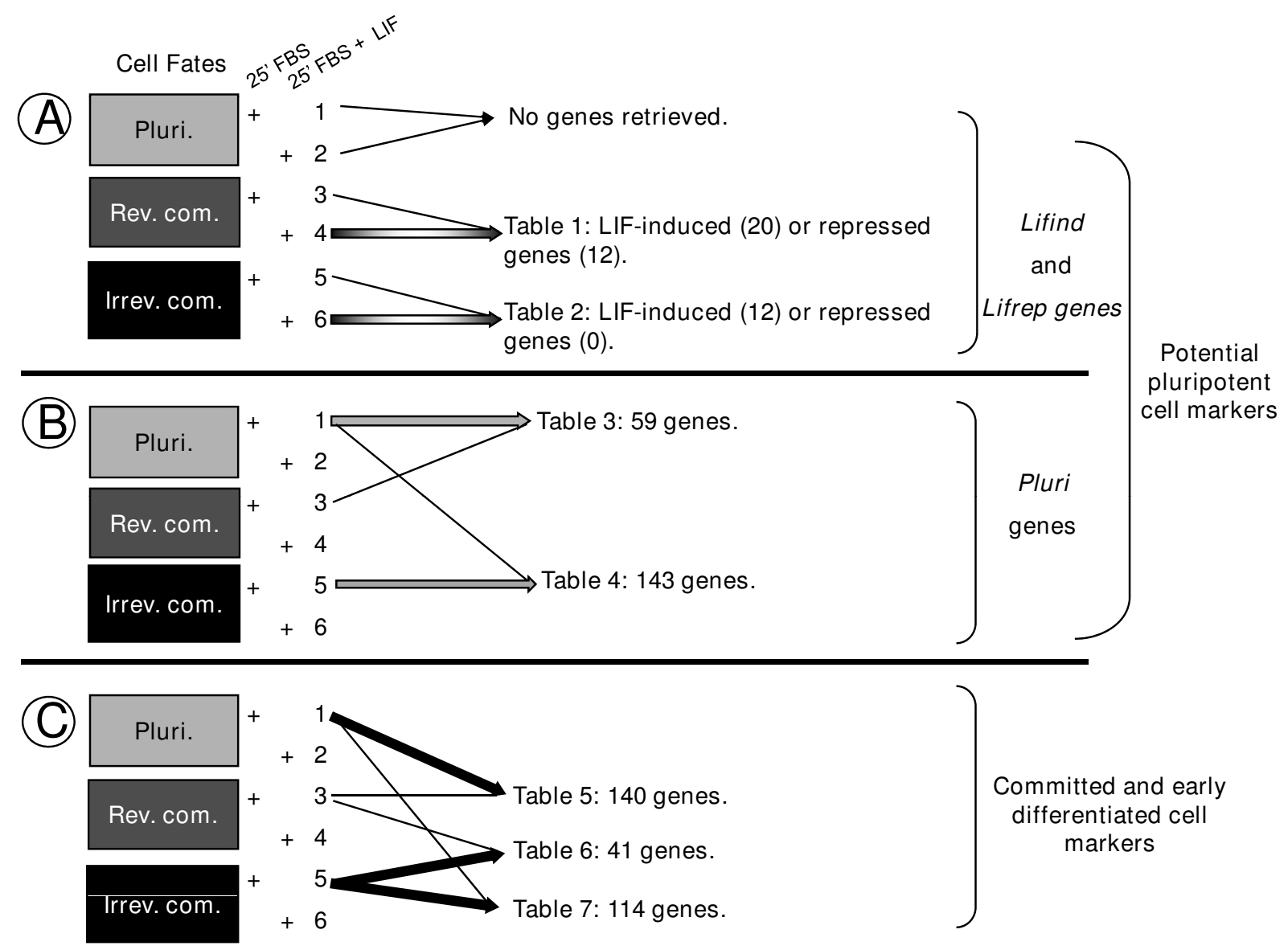

Figure 2

Summary of pair-wise comparisons. A) LIF-induced (Lifind) or repressed (Lifrep) genes, in pluripotent cells (samples I and 2) or after $24 \mathrm{~h}$ (samples 3 and 4) or $48 \mathrm{~h}$ (samples 5 and 6) of LIF withdrawal, B) Pluri. genes and C) Markers from reversibly and irreversibly committed cells, were retrieved by pair-wise comparisons after a student t-test analysis with the $\mathrm{p}$-value and fold change cut off as indicated for each Table, see Additional file I. Each thick line indicated the condition for which the number of genes has been filtered, after t-test analysis, versus the other condition. Pluri: Pluripotent; Rev.com.: Reversible commitment; Irrev. com.: Irreversible commitment.

egory of genes, whose expression is transiently induced in reversibly committed cells (see also below, in Figure 3). Table 7 includes genes induced at $48 \mathrm{~h}$ versus $24 \mathrm{~h}$ of LIF starvation. Some of these genes are specific of the irreversibly committed cells.

\section{3) Gene clustering of all conditions}

We performed an ANOVA (F-test) on data obtained under the different cell growth conditions. The expression profiles of highly significant differentially expressed genes [pvalue $<10^{-6}$ with a FDR (False Discovery Rate) of 1.48. $10^{-4} ; \mathrm{n}=292$ ] have been categorized using hierarchical clustering. This allowed to group genes with similar expression profiles, an indication of potential co-regula- tion and common functions [52]. Tree view representation of the clusters led to the identification of eight independent groups of genes (Figure 3). The upper dendrogram shows the expected clustering of the different cell growth conditions with the pluripotent state in one branch (pluri.), and the reversibly (r. com.) and irreversibly (ir. com.) committed conditions in the other branch. The complete list of genes of the cluster analysis is available (see Additional file 3).

Cluster 1 (similarity score $=0.7547$ ) includes genes whose expression, induced at $24 \mathrm{~h}$ of LIF starvation, is sustained at $48 \mathrm{~h}$ (Foxp1, Enpp3, Otx2, Pak1, Wt1, Gja1, Lef1 and $F z d 7$ ). Cluster 3 (similarity score $=0.8354$ ) defined the 


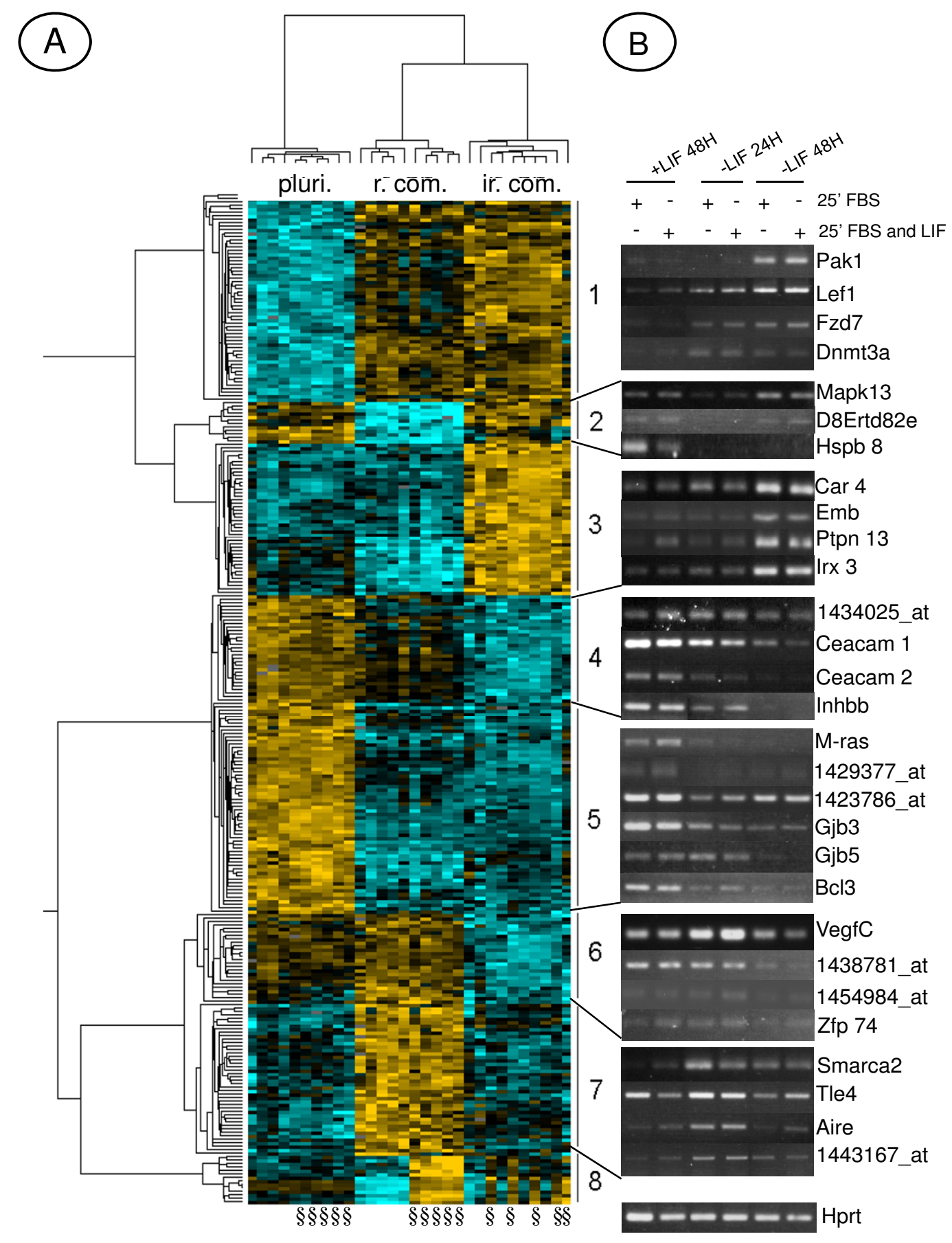

Figure 3

Identification of eight independent gene clusters. A) Each probe set is represented by a single row of colored boxes and single column represents each microarray. Cells with increasing up regulation colored with yellow of increasing intensity and increasing downregulation is colored with blues of increasing intensity. The similarity trees on the top (pluri.: Pluripotent; r. com.: reversible commitment; ir. com.: irreversible commitment) and on the left side, represent the similarity matrix of probe sets or microarrays. §: Samples treated $25 \mathrm{~min}$. with FBS and LIF. B) Semi-quantitative RT-PCR of a selection of genes from clusters I to 7. Representative results, from 4 independent experiments, are shown. 
differentiated markers specific of the irreversibly committed cells, like Car4, Embigin, Fgf5, Ptpn13, Irx3, Fgfr11, $R b p 7$, some of them corresponding to known cell lineage markers such as F $g f 5$.

Clusters 2 (similarity score $=0.7938$ ) and 7 (similarity score $=0.7109$ ), are the mirror image from each other and define new atypical gene behaviors. Modulation in the expression level of these genes was only detected in the reversibly committed cell population. Indeed, the expression profile of these genes is: "high-low-high" (Cluster 2) or "low-high-low" (Cluster 7) in "pluri - r.com - ir.com" cell growth conditions. Among genes from Cluster 2 we identified Vimentin, Hspb8 and Jund2. Genes from Cluster 7 include transcription factors like Mlr2, Aire, Tle4 and chromatin regulators as $B h c 80$, Smarca2. Genes from these clusters might be necessary to regulate the transition from pluripotent to irreversibly committed cells and their identification would not have been possible without the clustering of all data obtained in our experimental conditions.

Clusters 4 (similarity score $=0.8109), 5$ (similarity score $=$ $0.8170)$ and 6 (similarity score $=0.7163$ ) define genes highly expressed in pluripotent cells and whose expression level, was i) abruptly decreased $24 \mathrm{~h}$ following LIF starvation (in Cluster 5: Pim3, Fzd5, Sod2, Esrrb, Tcfcp2l1, Mras, Gjb3 and 5, Bcl3, Stat3, Smarcd3, Yes and Cd9), ii) progressively decreased, (in Cluster 4: Stmn1 and 2, Scarb2, Timp1, Pcolce, Tcl1 and Trps1) or iii) decreased only $48 \mathrm{~h}$ after LIF starvation (in Cluster 6: Lgals3, Cordon bleu, Vegfc, Zfp74, Hist1h1c). Genes from cluster 5 are named "Pluri" genes thereafter.

Cluster 8 (similarity score $=0.7488$ ) includes genes whose expression was induced by LIF in both reversibly or irreversibly committed cells. Only one gene (probe set 1446583_at) was found repressed by LIF in this analysis.

The regulated expression of a selection of genes from each cluster and Tables 1 and 2 (see Additional file 1) was validated by semi-quantitative RT-PCR (Figures 3B, 4A and 4B).

\section{4) Cell fate-independent and cell-specific Lifind genes}

To determine whether the Lifind genes from Table 1 (see Additional file 1) are modulated by LIF in other cellular context, we analysed their expression profile with the heatmapper tool, under our set of conditions (Figure 5A), and in an embryoid body (EB) kinetic analysis following LIF withdrawal, from day 1 to day 10 (Figure 5B). Indeed, we had previously shown that some LIF targets (like Socs3, Fos and JunB) are expressed, several days after LIF withdrawal, in differentiated cells [46]. In this study, we extended this analysis and showed that almost all the genes induced by LIF in reversibly and irreversibly com- mitted cells, are re-expressed, concomitantly with the reexpression of LIF and of its receptors (gp130 and gp190) at day 10 of EB differentiation (Figures 5B and 5C). In contrast, genes marked with an asterisk in Figure 5A are not re-expressed (see Figure 5B). Therefore, we have characterized two types of Lifind genes: those induced by LIF at $24,48 \mathrm{~h}$ and 10 days after LIF withdrawal and which correspond to cell fate-independant LIF targets [named hereafter "Pleio-Lifind" genes and including Socs3, Fos and $J u n B]$ and genes whose induction by LIF is cell-restricted [named hereafter "Spe-Lifind"genes] and which were not known, so far, as LIF targets.

\section{5) Regulation of "Pluri" genes in embryoid bodies kinetic following LIF withdrawal}

Genes from Cluster 5 (represented in Figure 6A), were also analysed with the heatmapper tool in the time course of EB differentiation (Figure 6B). Master genes, Oct4, Sox2 and Nanog, whose expression is stable up to day 2 (Sox2) or day 3 (Oct4 and Nanog) and which are therefore not present in cluster 5 , were manually added for this analysis. Three groups of genes were identified: i) those strictly expressed in pluripotent cells (red line, Cluster a), including pluripotent cell marker like Esrrb; ii) those reexpressed at day 10 of the EB diffentiation kinetic (blue line, Cluster b), including the LIF-dependent $C d 9$ gene [39], and iii) genes whose expression was higher in differentiated than in pluripotent cells (blue line, Cluster c), including Stat3. This analysis helps to identify relevant new genes potentially involved in the maintenance of ES cell pluripotency, since known pluripotent markers are present in each of these clusters.

\section{6) Analyses of Lifind and Pluri gene expression in Oct4 and Nanog knock-down experiments}

The overall expression level of Oct4 and Nanog was unaltered up to three days upon LIF withdrawal in the kinetic of embryoid bodies (Figure 6B). However, the recent finding that ES cells are heterogeneous for the expression of many markers, like NANOG but no OCT4, prompted us to determine whether the expression level of genes identified in this study could be directly modulated by these master genes. This should help to find a specificity of these core "pluripotent master genes" [53,54]. We have analysed expression profiles of Lifind and Pluri genes after knock-down of Nanog and Oct4 by RNAi. Availability of Affymetrix data, from Loh et al, [19], performed with mouse ES cells infected with lentivirus expressing shNanog or shOct4 silencing RNAs, allowed such an analysis. Heatmapper analyses were performed with Lifind (Figure 7A) or Pluri genes (Figure 7B). The expression of Lifind genes are either repressed like Ier2, Socs3, klf5 or Egr1 (Figure 7A, Cluster 1) or induced like Zfp36, Fos and Rasd1 (Figure 7A, Cluster 2) by Oct4 knock down. Remarkably, Ier3 is the only Lifind gene whose expression is repressed by Nanog 


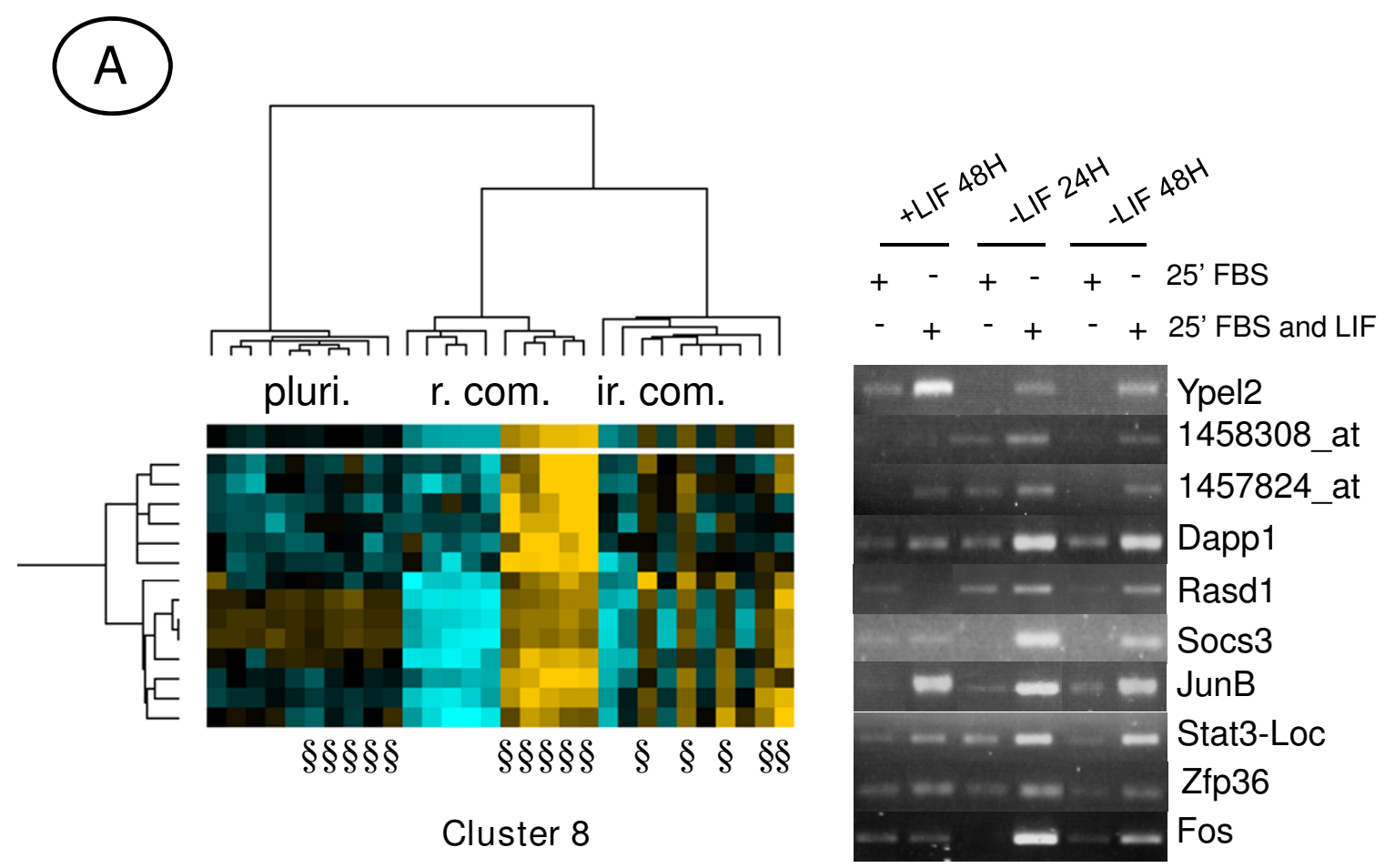

T-test Analysis

(Tables 1 and 2)

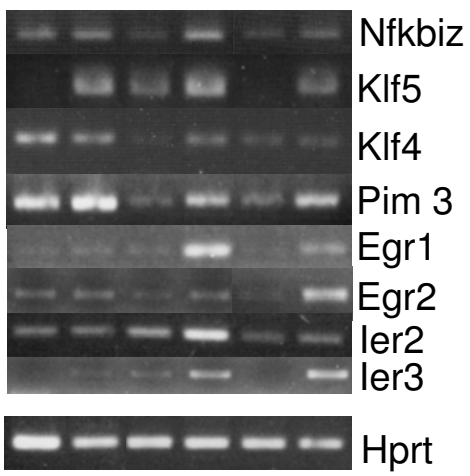

\section{Figure 4}

Highlights on Cluster 8. A) Tree view representation of Lifind genes, regulated similarly by LIF in r. com. (reversible commitment) and ir. com. (irreversible commitment) conditions and validation of a selection of genes by semi-quantitative RT-PCR, B) Validation of a selection of Lifind genes retrieved by the t-test analysis. §: Samples treated 25 min. with FBS and LIF. Representative results, from 4 independent experiments, are shown.

silencing. In addition, this analysis emphasizes the particularity of some Spe-Lifind genes (like Pabpc1, Plscr1, Dapp1 and Dyst) and of JunB, Sbno2 and Egr2 whose expression is altered neither by Oct4 nor by Nanog silencing.

A similar analysis has also been conducted with the Pluri genes (Figure 7B), highlighting their differential regulation by Oct4 or Nanog. Indeed, we identified 5 groups of genes whose expression is down (like Sox2, Irak3 and Susd2 in Figure 7B, Cluster 1) or up (like Cd9, Gjb3 and Gjb5 in Figure 7B, Cluster 5) regulated following Oct4 but not Nanog silencing or down regulated by independent silencing of both genes (like Esrrb, Ly6 and Sod2 in Figure $7 \mathrm{~B}$, Cluster 2 and part of Cluster 4 including Slc11a1, Nanog and Fblim1). The expression of only one gene (Ceacam1) was increased by Nanog silencing (Figure 7B, 

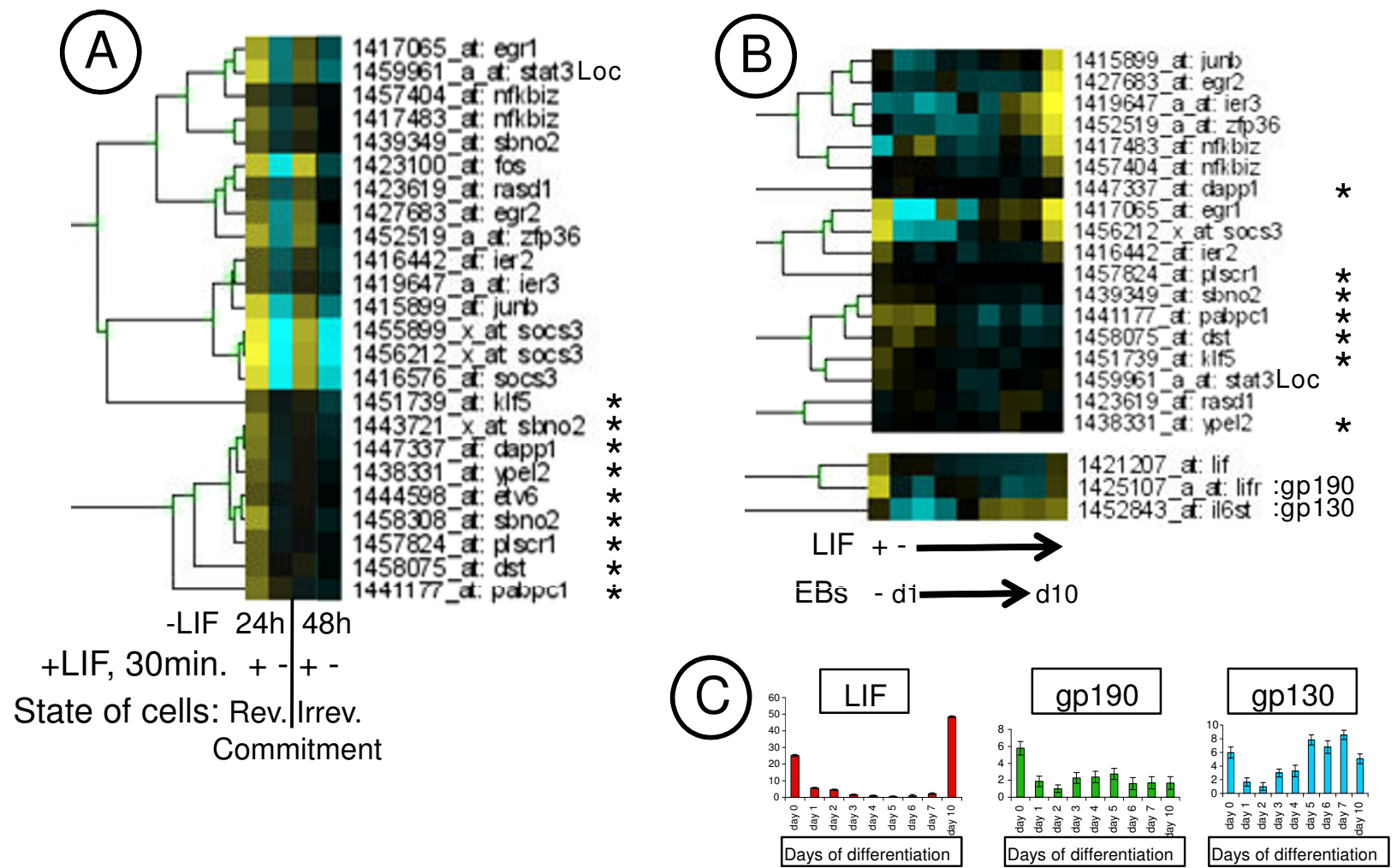

\section{Figure 5}

In silico analyses of Lifind genes in various microarray experiments. Tree view representation of Heatmapper analyses of Lifind genes retrieved from Table I and analysed with Affymetrix data from reversibly (rev.) and irreversibly (irrev.) committed cell populations A), and in a kinetic of LIF withdrawal [day I (dI) to day I0 (dI0) in EBs], B). The validation of the expression of LIF cytokine and of its composite receptor (gP I 30 and gp I90), performed by RT-qPCR on three independent experiments, is shown as histograms with standard deviations in $\mathbf{C}$ ). The asterisks point to genes not reinduced by LIF in differentiated cells ( $\mathrm{d} I 0 \mathrm{EBs})$.

Cluster 3). These analyses define novel gene categories, not similarly regulated by master genes, which might be part of novel sub-networks involved in the regulation of ES cell pluripotency.

\section{7) Effects of knock-down of a selection of Lifind and Pluri genes in pluripotent cells}

In silico analyses allowed us to select genes among the Lifind and Pluri genes for further functional studies. We focused our efforts on a selection of Spe-Lifind genes (Dapp1, Plscr1, Dyst, Pabpc1) and also included Ier3 owing to its particular expression profile in Oct4 and Nanog silencing experiments. Concerning the Pluri genes, we performed the experiments with genes specifically expressed in pluripotent cells such as Irak3, Susd2 and Ly6 and whose expression was affected by only one master gene (Oct4), except $L y 6$, which behaves as Esrrb, a recently identified pluripotent marker $[25,55,56]$. We have also included $T c f c p 211$, a transcription factor strictly expressed in pluripotent cells (Figure 6B, Cluster a).

We have tested the function of these genes using an RNA interference strategy. Endoribonuclease prepared (e) siRNAs [57] were generated, targeting the different genes. ES cells were transfected twice with each esiRNA and stained with Alkaline phosphatase (ALP) five days after the first transfection (see Additional file 4). Knock-down of Stat3 and Oct4 led to morphological cell differentiation (with loss of ALP staining), and proliferative defects similar to that observed when LIF was withdrawn for 4 to 5 days, consistent with their known function in maintaining pluripotency (positive controls). Knock-down of the various genes tested did not induce significant morphological changes, as shown for Ier3 as well as for the other genes tested (see Additional file 4 and results not shown). However, alteration in gene expression level (as shown in Fig- 


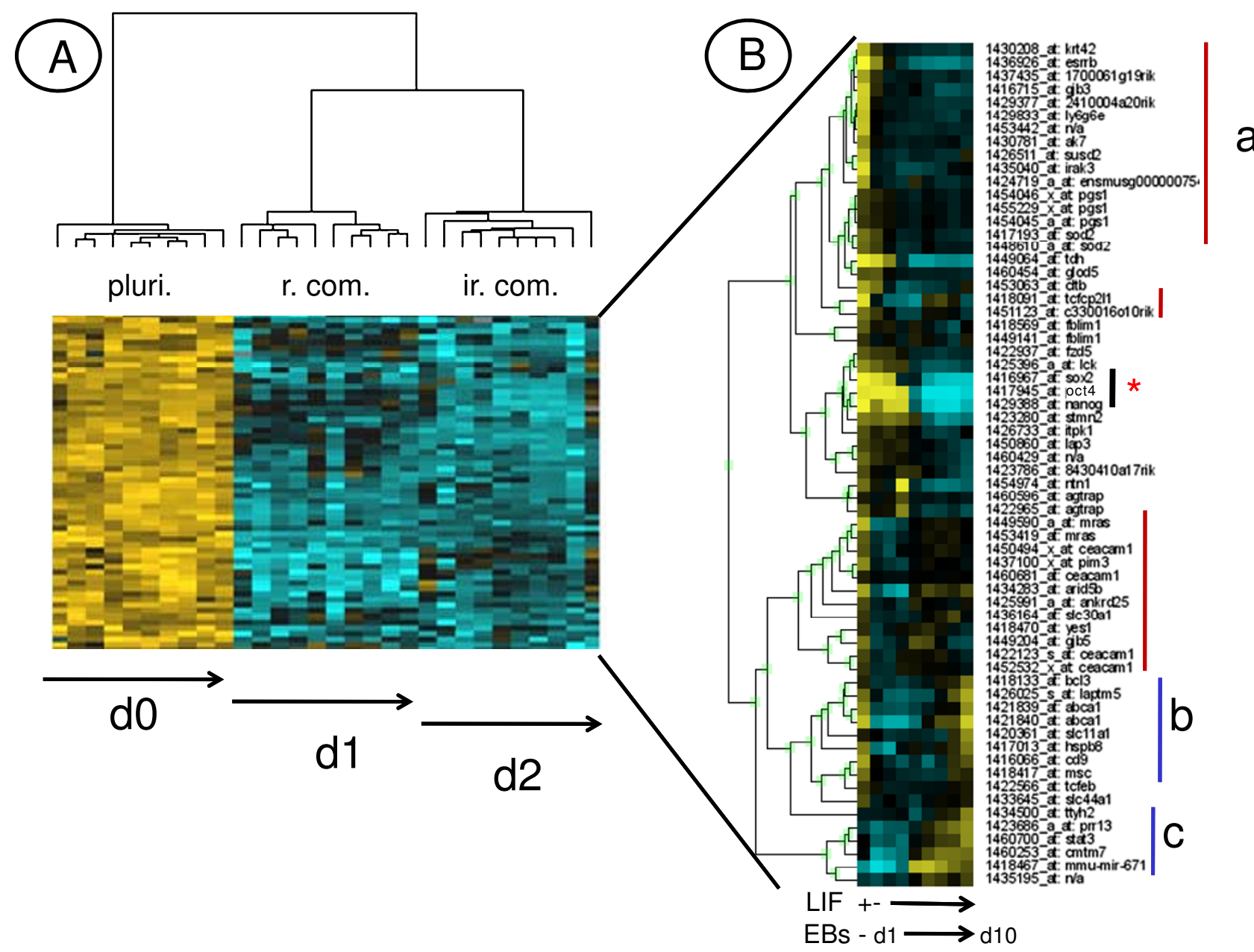

Figure 6

In silico analysis of Pluri genes. Heatmapper analysis of genes from Cluster 5 (as defined in Figure 3 and represented here in panel A) has been performed with Affymetrix data taken from the kinetic of LIF withdrawal (dI to dIO of EBs differentiation), B) Relevant clusters are highlighted by red (a) or blue lines (b and c). The asterisk points to three master genes, sox2, oct4 and nanog manually included in this analysis.

ure 3) occurred much earlier than morphological changes, which are observed at three days upon LIF withdrawal (see Additional file 4A) and as reported in other ES cell lines, $[47,58]$. This prompted us to analyse the effects of gene silencing on the expression of early differentiation markers. Expression level of Lef1, Pak1, Car4 and Dnmt3a, all induced at 24 or $48 \mathrm{~h}$ of LIF withdrawal (see Figure 3), was analysed after 5 days of transfection in ES cells grown with LIF. The expression of Nestin, Gata4, Gata6 and Sox17, induced at later times of LIF withdrawal, was also studied. The efficiency of the silencing of each esiRNA was determined by RT-qPCR and shown to be in the range of 50 to 80\% (see Additional file 5 and not shown). The expression of almost all the differentiation markers tested was modulated by the silencing of Stat 3 or Oct4. However, individual silencing of the selection of Lifind or Pluri genes led to no effects or modest up regulation of some of the tested differentiation markers (see Additional file 5).

\section{Discussion}

From pluripotent to irreversibly committed cells: The LIF impact

By gene profiling studies performed with pluripotent murine ES cells and with reversibly or irreversibly ESderived committed cells, treated or not with LIF, we end up with a new global view of the genetic program leading from pluripotent to differentiated cells, as summarized in Figure 8: When LIF is withdrawn for $24 \mathrm{~h}$, cells enter the commitment phase and the expression of 59 genes declines (like Bcl3, Klf4, Stat3, Yes, Esrrb, Nanog, M-ras, $F z d 5)$, while the expression of 140 genes increases (like Lef1, Otx2, Wt1, Dnmt3a, $b$ and Fzd7). When LIF is added 

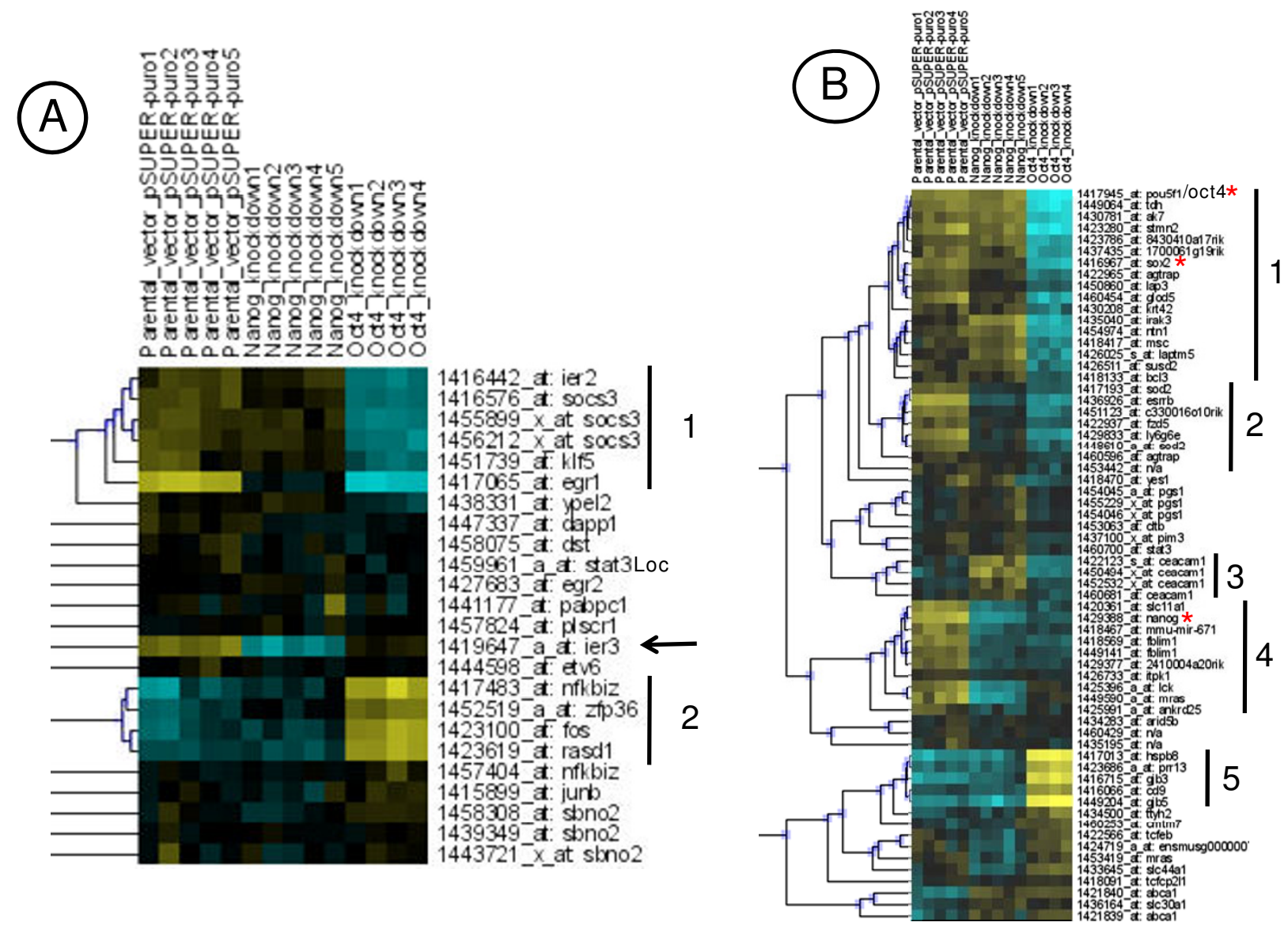

\section{Figure 7}

In silico analysis of Lifind and Pluri genes: Regulation by OCT4 or NANOG. Heatmapper analyses performed respectively with LifindA) and PluriB) genes whose level of expression was analysed in microarray experiments taken from Loh et al, [19]. Relevant clusters are marked with black lines and numbered. Color code is like in Figure 3. yellow: expression above the median; black: median expression; blue: expression below the median.

back at this stage, twenty genes are induced (like Socs3, Klf4 and 5, JunB, Egr1, 2, 3, Ier 1, 2, 3; Zfp36) and twelve are repressed. This type of treatment allows cells to maintain their pluripotent state, as illustrated by their ability to colonize blastocysts and produce chimera almost as efficiently as cells kept under the continuous presence of LIF $[24,38,45,47,59]$. When LIF is withdrawn for $48 \mathrm{~h}$, the set of genes repressed, in comparison with the pluripotent cells, is larger than at $24 \mathrm{~h}$ of LIF starvation. Some of these genes (16 genes, like Oct6, Lef1, Otx2, Wt1, Dnmt3a) are already expressed by reversibly committed cells suggesting that their sustained expression might be critical for the establishment of the differentiated state. Among them, Otx2 was recently shown to be a critical regulator of early cell differentiation [25]. LIF treatment of cells starved of LIF for $48 \mathrm{~h}$ does not reset the stemness program as shown by their inefficiency to form teratomas or colonize blastocysts $[45,59]$. Our statistical study reveals differences in the set of LIF targets induced after a $24 \mathrm{~h}$ or a $48 \mathrm{~h}$ period of LIF starvation. Indeed, only a portion of the genes identified in reversibly committed cells was induced by LIF in irreversibly committed cell population. In addition, the extent of LIF induction was less than half that observed in reversibly committed cells, despite the fact that STAT3 phosphorylation and activity remained very high in both situations. This suggests that activated STAT3 could regulate a cell-state-dependent pathway which locks cells in a differentiated state.

\section{Three LIF-dependent signatures}

Our analysis has allowed also to distinguish between SpeLifind (genes induced by LIF in a restricted cellular context), Pleio-Lifind (genes induced by LIF in various cellular context and potentially involved in pleiotropic effects of LIF) and Pluri genes. This last category corresponds to LIFdependent genes, not reinducible by LIF in the first $48 \mathrm{~h}$ 

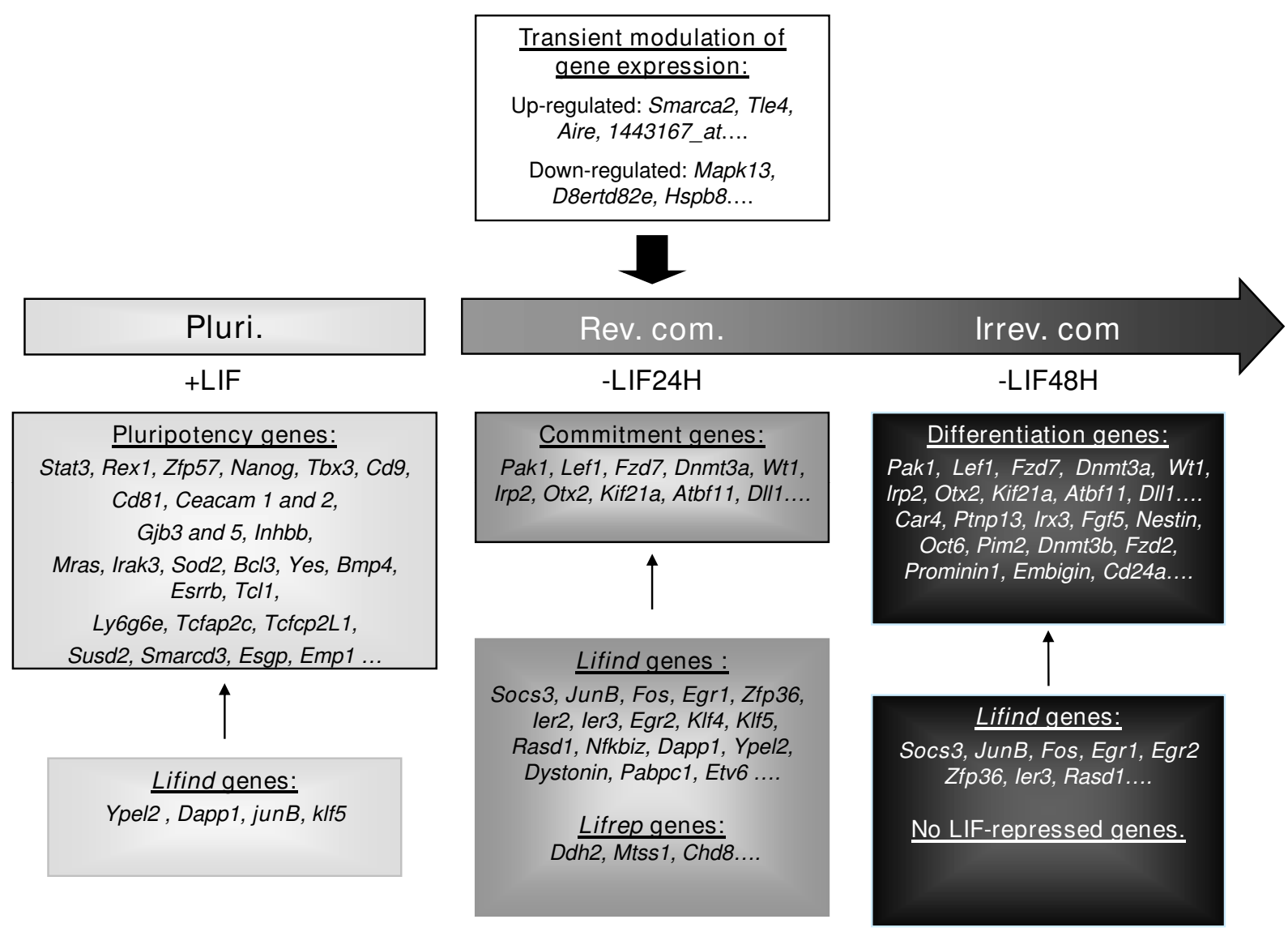

\section{Figure 8}

Highlights of microarray analyses performed in pluripotent, reversibly and irreversibly ES-derived committed cells, treated or not with LIF. A selection of genes regulated in each cell state is presented. Bolded genes are the pleio-Lifind genes, identified in the ES cell system or in other LIF sensitive cell types.

of differentiation (summary in Figure 8). Some of the Pleio-Lifind genes are known for their impact on stemness, [like Klf4 or Socs3 $[23,41,48]]$, in trophoblast differentiation (like Socs3, [60]) and for their activation in the M1 myeloid cell line, in which LIF is pro-differentiative (like JunB and Egr1 [61-63]). However, none of the Spe-Lifind genes has previously been identified as LIF targets. Many of these genes are not well characterized, and their potential responsiveness to LIF could help unravelling their function. In addition, the comparison of LIF regulated genes identified in our study with those reported in microarray analyses, performed on other cell types or tissue [cardiomyocytes [64], neurons [65] and uterus [66]], shows no overlap except stat3 (summary in Figure 9). However, both the different timing of LIF induction ( $25 \mathrm{~min}$. in our study versus several hours in these other studies) and cell context, $[48,67,68]$, might account for this absence of overlap. Our screen reveals also a partial overlap between
LIF targets identified in this study, and STAT3 targets, previously reported $[47,69]$ suggesting that LIF and STAT3 pathways might have various outcomes which are not yet fully identified, and that LIF-dependent response might not be under the sole control of STAT3.

Our screen revealed that there are few LIF-repressed genes. This emphasizes the point that LIF effects are regulated through the synthesis of repressors (e.g., Socs3). Mereover, new LIF-induced negative regulators might be critical for maintenance of cell pluripotency. Such a candidate could be $Z f p 36$, which encodes for a protein involved in mRNA stabilization through the ARE (Au Rich Element) sequence $[70,71]$. We found that a proper level of this protein was necessary to ensure survival of pluripotent cells since its overexpression led to cell death (our unpublished results). Along with the recent finding that ZFP36 regulates directly the stability of Ier3 mRNA [72], a new Lifind 


\begin{tabular}{|c|c|c|c|c|c|c|}
\hline \multirow[t]{2}{*}{ Authors } & Cell lines & Micro-array & Conditions & \multicolumn{2}{|c|}{ Retrieved genes } & Fonctional analysis \\
\hline & $\begin{array}{c}\text { Shp-2 } 246-110 \text { ES cell } \\
\text { line (hypersensitivity } \\
\text { and increased LIF- } \\
\text { stimulated } \\
\text { phosphorlation of } \\
\text { STAT3). }\end{array}$ & $\begin{array}{l}\text { Affymetrix Murine } \\
\text { Genome U74A } \\
\text { GeneChips }\end{array}$ & $\begin{array}{l}\text { Cells cultivated } \\
\text { without serum and } \\
\text { LIF for } 6 \mathrm{~h} \text { and next } \\
\text { stimulated with LIF } \\
\text { or PBS for } 45 \mathrm{~min}\end{array}$ & \begin{tabular}{|} 
LIF-induced genes: Socs3, Klf4, Sgk, Nmyc1, \\
Gtf2f2, Pim3, ler3, Gltscr2, Itch, Ccrn4l, Eif2s3y, \\
ler2, Zfp36l1, Sart1, 5430411K16Rik, Icam1, Rest, \\
1500034 J01Rik, Scospondin, Ppgb, Rab14, Mfng, \\
3830421F13Rik, Cd38
\end{tabular} & $\begin{array}{c}\text { LIF-repressed genes: Copg, Eif2s2, Tceb2, Hnrpc, } \\
\text { D1Pas1, Large, Foxo3, Sod1, Elovl6, Ywhae, } \\
\text { Gt(ROSA)26asSor }\end{array}$ & $\begin{array}{l}\text { ES cells overexpressing SOCS-3 had an } \\
\text { increased capacity to differentiate to } \\
\text { hematopoietic progenitors, rather than to self- } \\
\text { renew. In contrast, ES cells overexpressing KIf4 } \\
\text { had a greater capacity to self-renew based on } \\
\text { secondary embryoid body (EB) formation. }\end{array}$ \\
\hline \multirow{3}{*}{$\begin{array}{l}\text { Sekkai D. et al, } \\
2005 \\
\text { (Ref. } \mathrm{n}^{\circ} 47 \text { ) }\end{array}$} & \multirow{3}{*}{$\begin{array}{c}\text { ES Gs2 (Expressed } \\
\text { STAT3 dominant } \\
\text { negative in absence of } \\
\text { tetracycline) }\end{array}$} & \multirow{3}{*}{$\begin{array}{l}\text { In-house c-DNA chip } \\
\text { from CEA }\end{array}$} & $\begin{array}{l}16,24,72 \mathrm{~h} \\
\text { without LIF }\end{array}$ & \begin{tabular}{|} 
Pluripotency genes: Aes1, Zfp57, Zfp 3611, Stat3, \\
SH3-binding protein levell, cyclin D3, Prkg2, \\
CD97, Mfge8, Lrrfip1, Bcl3, ApoC1, Inhbb, \\
MARCKS-like protein, Gabarapl2, spp1, sept01, \\
Socs3, rex1, cd9
\end{tabular} & $\begin{array}{l}\text { Differentiation genes: Idb2, Idb1, Cdk1c, } \\
\text { mesoderm specific transcript, Leftyl, Tacsid1, } \\
\text { Crmp1, Cdx2, PTK7, Enolase 3, Ldh1, Gpx4 }\end{array}$ & \multirow{3}{*}{$\begin{array}{l}\text { Aes } 1 \text { gene is a direct transcriptional target of } \\
\text { Stat3 in ES cells. Stat } 3 \text { is recruited to the } \\
\text { promoter of aes } 1 \text { in ES cells and activate } \\
\text { transcription of aes } 1 .\end{array}$} \\
\hline & & & \begin{tabular}{|c|}
$16,24,72 \mathrm{~h}$ \\
without tetracycline
\end{tabular} & $\begin{array}{l}\text { Pluripotency genes: Fibronectin I, Asparagine } \\
\text { synthetase, Aes } 1, \text { ApoE }\end{array}$ & $\begin{array}{c}\text { Differentiation genes: Idb2, Idb1, Cdk1c, Leftyl, } \\
\text { protein kinase C, Crmp1, colla2, Itga2b, Atpla2, } \\
\text { Atp2a1, Tpm1, Tnni2, Acinin alpa1, Lgals3, } \\
\text { Tacstd1, Ldh1 }\end{array}$ & \\
\hline & & & $\begin{array}{c}\text { Combination of } 2 \\
\text { analysis (t-test and } \\
\text { clustering) }\end{array}$ & $\begin{array}{l}\text { Pluripotency genes: Aes, Inhbb, Psap, } \\
\text { MARCKS-like protein, Lrrfip1, sparc, Gjb5, Socs3, } \\
\text { Gabarapl2, Mylpf, Vdac1, Emd, Cryab }\end{array}$ & $\begin{array}{c}\text { Differentiation genes: Idb2, Idb1, Cdk1c, Leftyl, } \\
\text { cyclin G1, Atpla2, Tacstd1, Lamr1, Csda, ApoE, } \\
\text { Ank, Carbonic anhydrase } 3\end{array}$ & \\
\hline $\begin{array}{l}\text { Wright L.S. et } \\
\text { al, 2003 } \\
\left.\text { (Ref. } n^{\circ} 65\right)\end{array}$ & Human ItNCSctx & \begin{tabular}{|} 
Affymetrix HG-U133 \\
array
\end{tabular} & $\begin{array}{l}\text { ItNCSctx cultivated } \\
20 \text { weeks with EGF } \\
\text { and next EGF and } \\
+/ \text { - LIF for } 20 \text { weeks }\end{array}$ & \begin{tabular}{|} 
LIF-induced genes: immune response genes, \\
transcription factors [ $\mathrm{V}$-fos, STAT3, STAT1 and 9 \\
others genes], neural genes signaling pathways \\
genes, ER protein processing, cell adhesion \\
[S100 A10, Myosin VB, Lectin, galactoside-binding, \\
soluble, 3 (galectin 3), Annexin A2 (ANXA2), \\
S100A11, and 12 others genes..]
\end{tabular} & $\begin{array}{c}\text { LIF-repressed genes: Neurexin l-alpha protein, } \\
\text { Protein tyrosine phosphatase, receptor type C, } \\
\text { RGC32 protein (RGC32), Spondin } 1 \text { (f-spondin), } \\
\text { Highly similar to CLP, Cyclin D1, Activated } \\
\text { leucocyte cell adhesion molecule, Cysteine } \\
\text { dioxygenase, type } 1 \text { (CDO1), Epidermal growth } \\
\text { factor receptor (verb-b), CCystatin C (CST), } \\
\text { ATPase Na, K transporting, a2 poypeptide } \\
\text { (ATP1A2) }\end{array}$ & N.D. \\
\hline $\begin{array}{l}\text { Florhomen G. } \\
\text { et al, 2004 } \\
\left.\text { (Ref. } n^{\circ} 64\right)\end{array}$ & $\begin{array}{l}\text { Rat neonatal } \\
\text { cardiomyocytes }\end{array}$ & $\begin{array}{c}\text { Atlas }^{\mathrm{TM}} \text { Nylon cDNA } \\
\text { Expression Arrays } \\
\text { (Atlas Rat } 1.2 \text { Array) } \\
\text { Clontech }\end{array}$ & $\begin{array}{l}48 \mathrm{~h} \text { of stimulation } \\
\text { with or without LIF }\end{array}$ & $\begin{array}{c}\text { LIF-induced genes: STAT3, CaMKIV, PKC } \delta \text {, ID1, } \\
\text { Cathepsin B, BTG2, IMP-1, BNP, Clu, TNF-R1, IL- } \\
\text { 4R, NTR2, SSTR5, PMP22 }\end{array}$ & $\begin{array}{l}\text { LIF-repressed genes: CTK1, p55cdc, TGF- } \beta 1 \text {, ATP } \\
\text { synth, E-FABP, IGFBP-6, ACV, LPLR }\end{array}$ & N.D. \\
\hline $\begin{array}{l}\text { Sherwin J.R.A. } \\
\text { et al, 2004 } \\
\left.\text { (Ref. } n^{\circ} 66\right)\end{array}$ & $\begin{array}{l}\text { Left uterine horn at } \\
84 \mathrm{~h} \text { of } \\
\text { pseudopregnancy in } \\
\text { LIF-l- females }\end{array}$ & $\begin{array}{c}\text { Affymetrix U74av2 } \\
\text { oligonucleotide arrays }\end{array}$ & $\begin{array}{l}12 \mathrm{~h} \text { of treatment } \\
\text { with LIF or PBS }\end{array}$ & $\begin{array}{l}\frac{\text { LIF-induced genes: IGFBP-3, amphiregulin et }}{\text { immune response gene-1 }}\end{array}$ & & N.D. \\
\hline
\end{tabular}

Figure 9

A) Compilation of a selection of microarray data and comparison with our results. Microarray experiments have been compared with our analysis. Genes in common with those identified in our analysis are bolded. B) Comparison of Lifind genes in ES cells and other cell types and organ. This table is a compilation of results obtained in various LIFresponsive cell types (cardiomyocytes and neurons) and organ (uterus).

gene identified in that study, it is tempting to propose that differential stabilisation of mRNAs could have an impact on the survival of pluripotent ES cells.

\section{Lifind genes regulation by OCT4 or NANOG}

We have classified Lifind genes into different sub-groups depending on their differential regulation by Oct4 or Nanog (summary in Figure 10). Expression of almost none of the Spe-Lifind genes is modulated by the silencing of these two master genes, emphasizing their belonging to a LIF specific pathway $[18,20,73]$. However, the individual knock-down of four of these genes (Dapp1, Plscr1, Dst and Pabpc1) does not lead to morphological changes nor to a significant alteration in the expression of a selection of early differentiation markers. Disruption of all four genes together might be required before any effect becomes apparent. Alternatively, these genes could be involved in the reversibility of committed cells grown without LIF for $24 \mathrm{~h},[38,74]$, a potentiality not tested in the present study.

\section{Novel characteristics of Pluri genes and differential regulation by OCT4 or NANOG}

The Pluri genes retrieved in this analysis include genes previously shown to maintain cell pluripotency like Yes, Cd9,
Esrrb, Tcl1 and Tbx3 [21,25,33,39]) and many novel genes (summary in Figure 8). We show that Pluri genes could be endowed with new features, which might be relevant to explain cell fates. Indeed, while expression of known master genes (Oct4, Sox 2 and Nanog) is maintained for 2 or 3 days following LIF withdrawal, expression of almost all the genes identified in our analysis (Figure 3A, Cluster 5) is decreased on the first day of LIF withdrawal like Esrrb or Pim3, recently identified as new pluripotent genes $[25,75]$. The direct targets of Esrrb and Tcfcp2l1 (both in Cluster 5) were recently characterized, allowing the identification of novel regulatory complexes and stressing the potential importance of sub-networks to regulate cell pluripotency [55]. Also, some of these genes are reexpressed 10 days after LIF withdrawal, therefore becoming LIF responsive in these differentiated cells. In addition, the silencing of Oct4 or Nanog decreases the expression of many of these genes together, potentially explaining why the individual knock-down of some of these Pluri genes does not affect cell pluripotency.

We have identified genes whose expression depends of Oct4 only (like Irak3, Susd2) or of both Oct4 and Nanog (like Esrrb, Fzd5, Ly6 or Sod2) or of none of them. Genes whose expression is induced by Oct4 (including Gjb3, 


\section{A) Lifind genes}

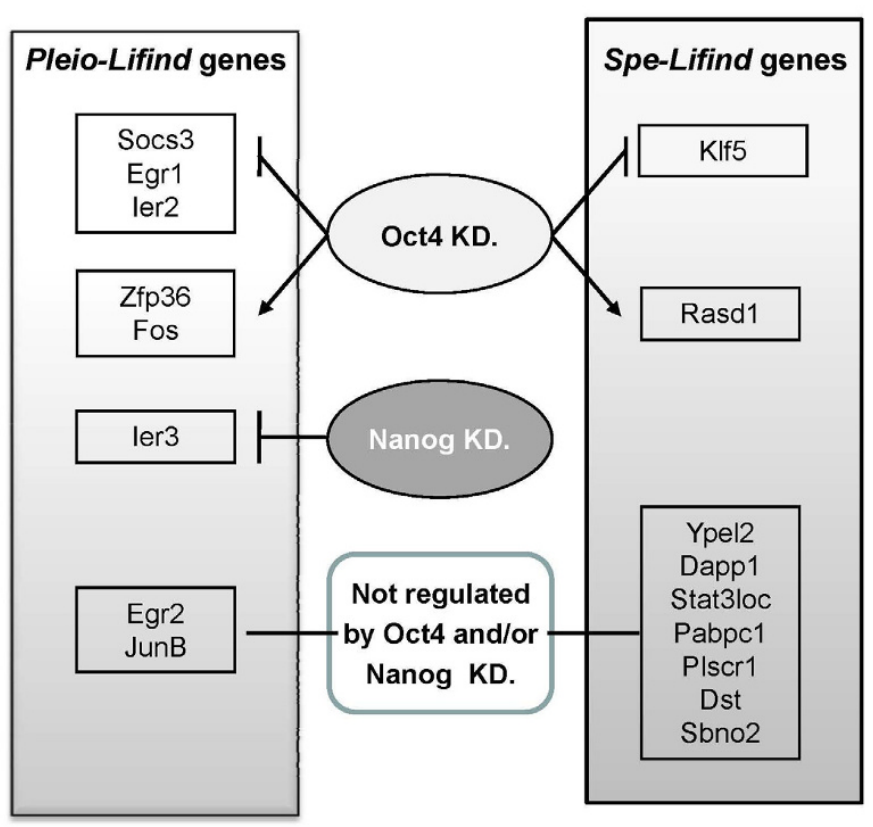

B) Pluri genes

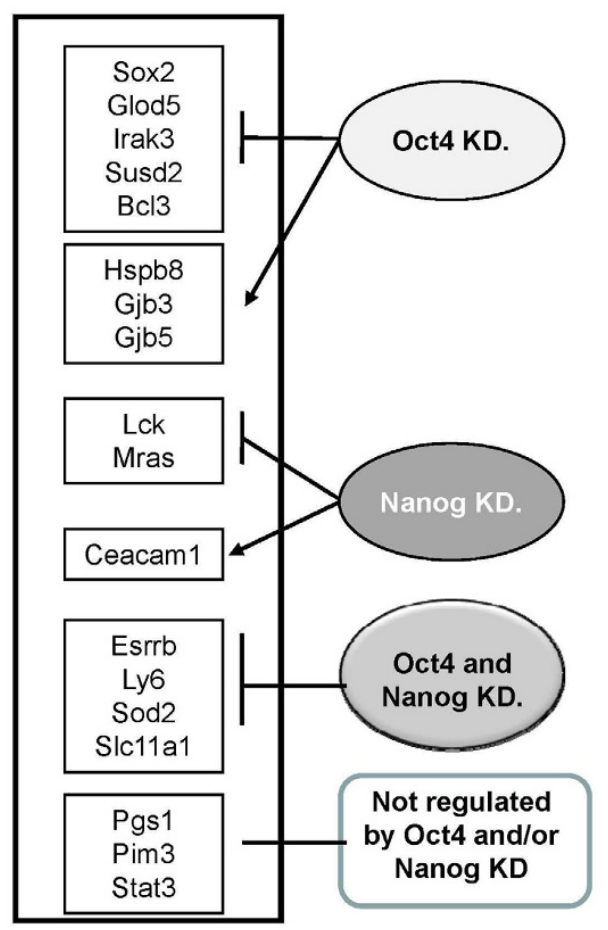

Figure 10

Lifind and Pluri gene expression in ES cells in which the expression of Oct4 or Nanog has been knocked-down. Summary of Pleio- and Spe-Lifind gene regulation A), and of Pluri gene regulation B), by Oct4 and/or Nanog, based on the heatmapper analysis.

Gjb5 and Cd9) or Nanog silencing (Ceacam1), have also been identified (data summarized in Figure 10). However, for unknown reasons, these genes were almost not expressed in pluripotent cells used in the study of Loh et al., [19] while highly expressed in the CGR8 cells used in our study and could be among genes whose expression fluctuates between various types of ES cells, as already described [76].

\section{4 h without LIF: a critical window for cell fate choices}

In this study, we also demonstrated that upon LIF withdrawal, cells go through a transition phase in which the expression of a new set of genes is modulated. Hierarchical clustering analysis was of fundamental importance for the characterization of two types of gene clusters, which displayed "high-low-high" (Figure 3A, cluster 2) or "lowhigh-low" (Figure 3A, cluster 7) expression levels in the three cell fates analysed "pluripotent, reversibly and irreversibly committed". Some of these genes, (Table 5, see additional file 1), from the Jumonji family, encoding for specific Histone demethylase, have recently been reported as being essential for the maintenance of ES cell pluripotency [77]. In addition, among genes from cluster 7, transcription factors ( $T c f e c, Z f p 532)$ and chromatin regulators (Bhc80, Smarca2 and Tle4) might be critical for the regulation of the expression of genes of cluster 2 (Mapk13, Hspb8, Vim and Jundm2) [78]. The functional role of these new gene clusters, to drive the transition from pluripotency to irreversible differentiation, will be a future goal.

\section{Conclusion}

Our work has provided a novel global view of LIF reponses in mES cells and in their early-derived derivatives and allowed the identification of various sets of LIF- 
induced (Lifind) and Pluripotency (Pluri) genes. We have also characterized sub-networks of genes whose expression is modulated while the master knot (composed of OCT4, SOX2 and NANOG) is still expressed, and which are partly under Oct4 and/or Nanog control. Furthermore, our study has led to the identification of gene clusters with atypical expression profiles, which desserve to be studied in details for their potential function in ES cell physiology. The recent demonstration that mouse ES cells are heterogeneous for the expression of different genes, like Rex1 [79], Nanog [53] and many others characterized by in situ hybridization [54], along with the identification of new genes from this study, open new roads for understanding and controlling ES cell plasticity.

\section{Methods \\ Cell culture, treatments for microarrays and reagents}

The CGR8 (feeder free) ES cell line (from 129SV mouse) was grown in DMEM, high glucose (Gibco), supplemented with $0.1 \mathrm{mM} \beta 2$ Mercaptoethanol, 10\% Foetal Bovine Serum (FBS), $400 \mu \mathrm{g} / \mathrm{ml}$ gentamycin and human LIF (500 pM). Cell medium was changed every other days.

For microarray experiments, plated ES cells were diluted at $10^{5} \mathrm{cell} / \mathrm{ml}$ in ES cell medium with or without LIF. The plating efficiency was similar in the presence and absence of LIF and cells have not been diluted during the $48 \mathrm{~h}$ of the experiment. At 24 or $48 \mathrm{~h}$ upon LIF withdrawal, cells were treated for $25 \mathrm{~min}$., with medium containing FBS or FBS and LIF, before harvesting. Cells grown in the complete medium with LIF were treated similarly after $48 \mathrm{~h}$ of cell growth.

The anti P-STAT3 Tyr705 (Cell signalling), P-STAT3 Ser 727 (gift from Dr. Frank, [80], anti-STAT3 (F-2, Santa Cruz), anti-OCT4 (Abcam) and anti-ERK2 (Santa Cruz) antibodies were used as recommended by the manufacturer.

For the differentiation of CGR8 ES cells by LIF withdrawal (embryoid body formation), hanging drop protocol was executed as described previously [81]. Briefly, an ES cell suspension of $2.5 \times 10^{4} \mathrm{cells} / \mathrm{ml}$ was prepared in Iscove's modified Dulbecco's Medium (IMDM) supplemented with $20 \% \mathrm{FBS}, 1 \%$ non-essential amino acids (vol/vol), 2 mM L-glutamine, and $100 \mu \mathrm{M} \beta$-ME. Of this ES cell suspension, $20 \mu \mathrm{l}$ was spotted on the inside of the upper lid of a $10 \mathrm{~cm}$ bacteriologic dish and then covered over its bottom dish containing $5 \mathrm{ml}$ phosphate-buffered saline. On day 2, the formed multicellular Embryoid Bodies (EBs) were transferred into suspension in a new dish with IMDM supplemented with $20 \%$ FBS, $1 \%$ non-essential amino acids (vol/vol), $2 \mathrm{mM} \mathrm{L-glutamine,} \mathrm{and} 100 \mu \mathrm{M} \beta$ ME. On day 7 , the EBs were plated on gelatin coated tissue culture dishes. RNA was isolated from ES cells (main- tained with LIF, d0) and from differentiating EBs [cultured in the absence of LIF for one day (d1) to day 10 (d10)] on an exact regular interval of 24 hours.

Microarray experiments: Hybridization and data analysis Total RNAs were prepared with the Qiagen column kit (Qiagen) and treated with DNAse (5 U/100 $\mu \mathrm{g}$ RNA, Sigma). Biotinylated cRNA was prepared according to the standard Affymetrix protocol (Expression Analysis Technical Manual, 1999; Affymetrix). In brief, doublestranded cDNA was synthesized from $10 \mu \mathrm{g}$ total RNA using the SuperScript Choice System from InVitrogen and the Affymetrix T7- $(\mathrm{dT})_{24}$ primer which contains a T7 RNA polymerase promoter attached to a poly-dT sequence. Following phenol/chloroform extraction and ethanol precipitation, the cDNA was transcribed into biotin-labeled cRNA using the Retic Lysate IVT ${ }^{\mathrm{TM}}$ kit (Ambion Inc., Woodward Austin, TX, USA). The cRNAs produced were purified using RNeasy kit (Qiagen) and fragmented to an average size of 30-50 bases according to Affymetrix recommendations. $15 \mu \mathrm{g}$ of fragmented cRNAs were hybridized for 16 hr at $45^{\circ} \mathrm{C}$ on the Mouse Genome 4302.0 Array. This array integrates 45101 probe sets, including 26275 sequences characterised in Entrez databases and 5069 anonymous ESTs. Arrays have been washed and stained in the Affymetrix Fluidics Station 450 and further scanned using the Affymetrix Gene-Chip scanner 30007 G. The image data were analyzed with the GeneChip ${ }^{\circledR}$ Operating Software (GCOS) using Affymetrix default analysis settings. Arrays - after passing the quality control - have been commonly normalized by the log scale robust multiarray analysis (RMA, [49]). After outlier removal using the Nalimov test at $\mathrm{p}<0.001$, a parametric ANOVA (F-test) has been applied to get global expression differences between the six different conditions. Multiple testing correction has been performed using the Benjamini-Hochberg procedure [50]. Hierarchical clustering of expression values of probe sets highly significant, differentially expressed in the ANOVA $\left(\mathrm{n}=292\right.$; pvalue $<10^{-6}$ and FDR $<1,48 \cdot 10^{-4}$ ) was performed by using Cluster version 2.11 [52] applying mean-centering and normalization of genes and arrays before average linkage clustering with uncentered correlation. To detect distinct expression differences between the growth conditions, paired Student t-tests of transcripts differentially expressed in ANOVA (FDR < $0,05)$ have been applied. Student t-test p-values and fold changes between the conditions, averages and standard deviations for each condition have been documented.

\section{Heatmapper analysis}

Heatmapper tool allows a graphical representation of the level of expression of many selected genes across a number of samples from various experimental conditions, as they have been obtained with similar DNA microarrays (eg: A430 2.0) [82]. The mean "signal" value 
from 3 independent experiments obtained from Affymetrix DNA analysis [(arrays A430 2.0: d0 to d10 of LIF withdrawal kinetic on embryoid bodies, (Sachinidis, A. et al, unpublished results)] have been compared with our current data analysis results. A Web-based tool that allows i) quick browsing of user-provided gene sets, ii) standard hierarchical clustering [52] and iii) heatmap-visualisation across multiple data sets, has been created and used for performing this study. This data analysis environment is currently being developped further into a systematic mouse stem cell data analysis atlas (R. Kolde and J. Vilo, unpublished results). Similarly, samples from Affymetrix data of Loh et al, [19], available at GEO data base under the access number: GSE4189, have been added in the interface created, as a way to perform analyses as shown in Figure 7.

\section{Cell lysates, Western blots and Band Shift experiments}

Plated cells were rinced twice with room temperature PBS and lysed directly in mild RIPA buffer (PBS, $1 \%$ triton, $1 \%$ NP40, 0.05\% SDS, $1 \mu \mathrm{g} / \mathrm{ml}$ protease inhibitor cocktail, 1 mM Pefabloc, $20 \mathrm{mM} \mathrm{NaF}, 1 \mathrm{mM}$ Na vanadate) and centrifuged $10 \mathrm{~min}$ at $10000 \mathrm{rpm}$. Cell lysates were resolved by SDS-PAGE and electro-transferred onto nitrocellulose membranes. Proteins were reacted with the different antibodies, as recommended by the manufacturers. Band shift experiments have been performed with nuclear cell lysates as described [38], with the SIE DNA probe, a high affinity DNA binding site for STAT3. Band shifs were performed in the presence of a $100 \times$ molar excess of unlabelled wild type (wt) or mutated $(\mathrm{m})$ competitor oligonucleotides encompassing the SIE sequence.

\section{Semi-quantitative RT-PCR and RT-qPCR}

Total RNAs from adherent ES cells were prepared with the Qiagen column kit (Qiagen) and treated with DNAse (5 $\mathrm{U} / 100 \mu \mathrm{g}$ RNA, Sigma). Total RNAs $(5 \mu \mathrm{g})$ were reversetranscribed (RT) with random hexameric primers and the MLV Reverse Transcriptase (Sigma). The RT reaction products were used for PCR with specific primer sets as described [48]. Sequences of primers used for all the genes tested in semi-quantitative RT-PCR (shown in Figure 3) are in Additional file 6.

Quantification, of the extend of Knock-down and of the expression of differentiation markers (see Additional file 5), was performed by RT-qPCR with the MX4000 system (Stratagene) as previously described [83]. The relative expression of the genes of interest was deduced of the $\mathrm{Ct}$ using the $\Delta \Delta \mathrm{Ct}$ method with Hprt house-keeping gene as the reference. Sequences of primers used in RTq-PCR are in Additional file 7.

The validation of the expression of LIF cytokine and of its receptors by RT-qPCR analysis (shown in Figure 5C) was performed with the ABI Prism 7500 Fast System (Applied Biosystems, Foster City, CA). $1 \mu \mathrm{g}$ total mRNAs of ES cells and of EBs, obtained from 3 independent experiments (biological triplicates), were reverse transcribed with ThermoScript $^{\mathrm{TM}}$ Reverse Transcriptase (Invitrogen, Karlsruhe, Germany). Then real-time PCR was performed with technical triplicates for every sample using TaqMan Gene Expression Assays (Applied Biosystems, Foster City, CA). The Gene Expression Assays used were Lif (Mm00434761_m1), Lif receptor (gp190) (Mm00442940_m1), Interleukin 6 signal transducer (gp130) (Mm00439668_m1) and Gapdh (Mm99999915_g1). $C_{t}$ values of each qPCR reaction from the target gene were normalized with the respective $\mathrm{C}_{t}$ values of the housekeeping gene, Gapdh, that ran in the same reaction plate to obtain the $\Delta \mathrm{C}_{\mathrm{t}}$ value. The fold change was calculated as follows: fold change $=2-(\Delta \mathrm{Ct}$ gene1 $-\Delta \mathrm{Ct}$ gene2). The $\Delta \mathrm{C}_{\mathrm{t}}$ of the gene in the sample with the lowest expression is used as $\Delta \mathrm{Ct}$ gene2 to calculate the fold change using the above formula. The resulting fold change is expressed as mean $\pm \mathrm{SD}$.

\section{RNAi experiments}

Endoribonuclease-prepared short interfering RNA (esiRNA) was synthesized according to the protocol described in [57]. Briefly, selected transcripts were analysed with the software program Deqor [84] to identify the best region for esiRNA synthesis. Primers with appending T7-RNA polymerase-tags were designed and used to amplify gene specific PCR products of about 500 bp in length. These fragments were used to generate dsRNA that was subsequently digested to esiRNAs with $E$. coli RNaseIII. The esiRNA was purified and used to transfect ES cells using Lipofectamine 2000. ES cells were plated in complete medium without antibiotics, on gelatinized 24-wells dishes at day 0 , to achieve $60-70 \%$ confluency on the day of transfection (day 1). $150 \mathrm{ng}$ of esiRNA (diluted in qsp $50 \mu \mathrm{l}$ of serum-free DMEM), was mixed with $1 \mu$ l of Lipofectamine 2000 (diluted in qsp 50 $\mu \mathrm{l}$ of serum-free DMEM). The mixtures were incublated at room temperature for $20 \mathrm{~min}$. and then added to freshly trypsinised ES cell culture, in suspension in $400 \mu \mathrm{l}$ of complete medium (with serum and LIF) without antibiotics. Medium was changed on day 2 and cells were re-transfected on day 3. Cells were harvested for RNA preparation or fixed on day $5,10 \mathrm{~min}$. at $4{ }^{\circ} \mathrm{C}$ in $2 \%$ formaldehyde/ $0.2 \%$ glutaraldehyde in PBS and stained with the Alkaline Phosphatase kit (Sigma-Aldrich, 86R-1KT) according to the manufacturer.

Primer sequences used for esiRNA synthesis are available on request. 


\section{Abbreviations}

BMP: Bone Morphogenetic Protein; Car4: Carbonic anhydrase 4; CREB: CAMP Responsive Element Binding; Dapp1: Dual adaptator for PY and PI3K; Dnmt3a: DNA methyltransferase 3a; Dst: Dystonin; ERK: Extracellular signal Regulated Kinase; EB: Embryoid Body; EST: Expressed Sequence Tag; esiRNA: endoribonuclease-prepared short interfering (esi) RNA; FBS: Fœtal Bovine Serum; Ier3: Immediate early response 3; Irak3: Interleukin-1 receptor-associated kinase 3; Lef1: Lymphoid enhancer binding factor 1; LIF: Leukemia Inhibitory Factor; Ly6gGe (Ly6): Lymphocyt antigen 6 complex; mES: mouse Embryonic Stem; Oct4: Octamer 4; Pak1: P21 (cdkn1a)-activated kinase 1; PI3K: Phosphatidyl-Inositol 3-Kinase; Pabpc1: PolyA binding protein, cytoplasmic1; Plscr1: Phospholipid scramblase 1; RSK: Ribosomal S6 Kinase; Susd2: Sushi domain containing 2; Socs3: Suppressor of cytokine signalling 3; Sox2: Sry-related high mobility group (HMG)-box protein-2; STAT3: Signal Transducer and Activator of Transcription 3; Tcfcp2l1 (Tcf): Transcription factor CP2-like 1.

\section{Authors' contributions}

MT, CS, BG, XG participated in cell culture, RNA preparations for affymetrix experiments, validation of the data and functional tests, LD, FB provided the esiRNA materials and elaborated the transfection procedure for esiRNA transfection, MXD, AS, JH provided data for the EBs experiments and did validation of expression profiles of LIF and LIFR genes, $\mathrm{OH}, \mathrm{NB}$, HS performed the Affymetrix experiments, the statistical analyses and the cluster analysis, RK, JV provided the WEB site for heatmapper analysis, HB conceived the global affymetrix strategy, designed experiments, organized the coordination and wrote the manuscript. All authors read, corrected and approved the final manuscript.

\section{Additional material}

\section{Additional file 1}

Tables 1 to 7: listing of significant regulated genes following $t$-test analyses.

Click here for file

[http://www.biomedcentral.com/content/supplementary/14712164-10-73-S1.pdf]

\section{Additional file 2}

Characterisation of Stat3Loc: probe set number: 1459961_a_at. Localisation of the sequence corresponding to this probe set, on the mouse genome.

Click here for file

[http://www.biomedcentral.com/content/supplementary/14712164-10-73-S2.pdf]

\section{Additional file 3}

Complete list of genes shown in the Figure $3 \mathrm{~A}$.

Click here for file

[http://www.biomedcentral.com/content/supplementary/1471-

2164-10-73-S3.pdf]

\section{Additional file 4}

Morphological changes of Alkaline phosphatase stained cells in various cell growth conditions (LIF withdrawal kinetic and knock-down of Oct4, Stat3 and Ier3 in the presence of LIF).

Click here for file

[http://www.biomedcentral.com/content/supplementary/1471-

2164-10-73-S4.pdf]

\section{Additional file 5}

Effects of the knock-down of a selection of Lifind and Pluri genes on the expression level of various committed and differentiation markers. Click here for file

[http://www.biomedcentral.com/content/supplementary/14712164-10-73-S5.pdf]

\section{Additional file 6}

List of primers used for semi-quantitative RT-PCR analysis. Click here for file

[http://www.biomedcentral.com/content/supplementary/14712164-10-73-S6.pdf]

\section{Additional file 7}

\section{List of primers used for RT-qPCR experiments.}

Click here for file

[http://www.biomedcentral.com/content/supplementary/14712164-10-73-S7.pdf]

\section{Acknowledgements}

We thank all colleagues from FungenES consortium for fruitful discussions, gift of materials and sharing of unpublished data. A particular thanks to Pierre Savatier, Niki Kretsovali, Melanie Welham and Francis Stewart for sharing unpublished informations and and additional thanks to Melanie Welham for her helpful comments and corrections of the manuscript. Thanks also to members of the UMR-CNRS-5I64-CIRID and in particular to Jean François Moreau for helpful insights and careful reading of the manuscript and Sophie Daburon for providing supernatant of $\mathrm{CHO}$ cells ovexpressing human LIF. We thank also Austin Smith for the gift of the CGR8 cell line, and Remi Laporte, an undergraduate student, for providing to us pictures of cells. HB is also grateful to Charlotte Hauss and Beatrice Reinhardt for their early contribution in this work.

This work was funded by the European consortium FungenES (6 th Framework, project $n^{\circ}$ LSHG-CT-2003-503494, Coordinator: Professor Jurgen Hescheler), CNRS, University of Bordeaux, the Ligue National contre le Cancer, comité de Gironde and Comité du Languedoc-Roussillon, the Region Aquitaine and the IFR 66. MT was financed by a FungenES fellowship, BG by a University of Bordeaux 2 fellowship (ATER) and next a FungenES fellowship and CS by a Region Aquitaine fellowship.

\section{References}

I. Bradley A, Zheng B, Liu P: Thirteen years of manipulating the mouse genome: a personal history. Int J Dev Biol 1998, 42(7):943-950. 
2. Smith AG: Embryo-derived stem cells: Of Mice and Men. Annu Rev Cell Dev Biol 200I, I 7:435-462.

3. Wobus AM, Boheler KR: Embryonic stem cells: prospects for developmental biology and cell therapy. Physiol Rev 2005, 85(2):635-678.

4. Boiani M, Scholer HR: Regulatory networks in embryo-derived pluripotent stem cells. Nat Rev Mol Cell Biol 2005, 6(I I):872-884

5. Niwa $\mathrm{H}$ : How is pluripotency determined and maintained? Development 2007, 134(4):635-646.

6. Hao J, Li TG, Qi X, Zhao DF, Zhao GQ: WNT/beta-catenin pathway up-regulates Stat3 and converges on LIF to prevent differentiation of mouse embryonic stem cells. Dev Biol 2006 290(I):8I-9I.

7. Ogawa K, Nishinakamura R, Iwamatsu $Y$, Shimosato D, Niwa H: Synergistic action of Wnt and LIF in maintaining pluripotency of mouse ES cells. Biochem Biophys Res Commun 2006, 343(1):159-166.

8. Singla DK, Schneider DJ, Lewinter MM, Sobel BE: wnt3a but not wnt II supports self-renewal of embryonic stem cells. Biochem Biophys Res Commun 2006, 345(2):789-795.

9. Boeuf H, Hauss C, Graeve FD, Baran N, Kedinger C: Leukemia inhibitory factor-dependent transcriptional activation in embryonic stem cells. J Cell Biol I997, | 38(6): | 207-I2I7.

10. Niwa H, Burdon T, Chambers I, Smith A: Self-renewal of pluripotent embryonic stem cells is mediated via activation of STAT3. GenesDev 1998, 12:2048-2060.

II. Matsuda T, Nakamura T, Nakao K, Arai T, Katsuki M, Heike T, Yokota T: STAT3 activation is sufficient to maintain an undifferentiated state of mouse embryonic stem cells. Embo J 1999 , I 8(1 5):426I-4269.

12. Ying QL, Nichols J, Chambers I, Smith A: BMP induction of Id proteins suppresses differentiation and sustains embryonic stem cell self-renewal in collaboration with STAT3. Cell 2003, I I5(3):28I-292

13. Chambers I: The molecular basis of pluripotency in mouse embryonic stem cells. Cloning Stem Cells 2004, 6(4):386-391.

14. Kristensen DM, Kalisz M, Nielsen JH: Cytokine signalling in embryonic stem cells. Apmis 2005, I I 3 ( I I- | 2):756-772.

15. Chambers I, Colby D, Robertson M, Nichols J, Lee S, Tweedie S, Smith A: Functional expression cloning of Nanog, a pluripotency sustaining factor in embryonic stem cells. Cell 2003, I I3(5):643-655.

16. Mitsui K, Tokuzawa Y, Itoh H, Segawa K, Murakami M, Takahashi K, Maruyama M, Maeda M, Yamanaka S: The homeoprotein Nanog is required for maintenance of pluripotency in mouse epiblast and ES cells. Cell 2003, I I 3(5):63I-642.

17. Rodda DJ, Chew JL, Lim LH, Loh YH, Wang B, Ng HH, Robson P: Transcriptional regulation of nanog by OCT4 and SOX2. Biol Chem 2005, 280(26):2473।-24737.

18. Boyer LA, Lee TI, Cole MF, Johnstone SE, Levine SS, Zucker JP, Guenther MG, Kumar RM, Murray HL, Jenner RG, Gifford DK, Melton DA Jaenisch R, Young RA: Core transcriptional regulatory circuitry in human embryonic stem cells. Cell 2005, I22(6):947-956.

19. Loh YH, Wu Q, Chew JL, Vega VB, Zhang W, Chen X, Bourque G, George J, Leong B, Liu J, Wong KY, Sung KW, Lee CW, Zhao XD, Chiu KP, Lipovich L, Kuznetsov VA, Robson P, Stanton LW, Wei CL, Ruan Y, Lim B, Ng HH: The Oct4 and Nanog transcription network regulates pluripotency in mouse embryonic stem cells. Nat Genet 2006, 38(4):43I-440.

20. Pan G, Li J, Zhou Y, Zheng H, Pei D: A negative feedback loop of transcription factors that controls stem cell pluripotency and self-renewal. Faseb / 2006, 20(10): I730-1732

21. Anneren C, Cowan CA, Melton DA: The Src family of tyrosine kinases is important for embryonic stem cell self-renewal. Biol Chem 2004, 279(30):31590-3I598.

22. Cartwright $P$, McLean C, Sheppard A, Rivett D, Jones K, Dalton $S$ : LIF/STAT3 controls ES cell self-renewal and pluripotency by a Myc-dependent mechanism. Development 2005, I32(5):885-896.

23. Li Y, McClintick J, Zhong L, Edenberg HJ, Yoder MC, Chan RJ: Murine embryonic stem cell differentiation is promoted by SOCS-3 and inhibited by the zinc finger transcription factor KIf4. Blood 2005, I05(2):635-637.

24. Palmqvist L, Glover CH, Hsu L, Lu M, Bossen B, Piret JM, Humphries RK, Helgason CD: Correlation of murine embryonic stem cell gene expression profiles with functional measures of pluripotency. Stem Cells 2005, 23(5):663-680.

25. Ivanova N, Dobrin R, Lu R, Kotenko I, Levorse J, DeCoste C, Schafer $X$, Lun $Y$, Lemischka IR: Dissecting self-renewal in stem cells with RNA interference. Nature 2006, 442(7 I02):533-538.

26. Walker E, Ohishi M, Davey RE, Zhang W, Cassar PA, Tanaka TS, Der SD, Morris Q, Hughes TR, Zandstra PW, Stanford WL: Prediction and testing of novel transcriptional networks regulating embryonic stem cell self-renewal and commitment. Cell Stem Cell 2007, I(I):7I-86

27. Anisimov SV, Tarasov KV, Tweedie D, Stern MD, Wobus AM, Boheler KR: SAGE Identification of Gene Transcripts with Profiles Unique to Pluripotent Mouse RI Embryonic Stem Cells. Genomics 2002, 79(2): $169-176$

28. Tanaka TS, Kunath T, Kimber WL, Jaradat SA, Stagg CA, Usuda M, Yokota T, Niwa H, Rossant J, Ko MS: Gene expression profiling of embryo-derived stem cells reveals candidate genes associated with pluripotency and lineage specificity. Genome Res 2002, I 2(1 2): | $92 \mid-1928$.

29. Sharov AA, Piao Y, Matoba R, Dudekula DB, Qian Y, VanBuren V, Falco G, Martin PR, Stagg CA, Bassey UC, Wang Y, Carter MG, Hamatani T, Aiba K, Akutsu H, Sharova L, Tanaka TS, Kimber WL, Yoshikawa T, Jaradat SA, Pantano S, Nagaraja R, Boheler KR, Taub D, Hodes RJ, Longo DL, Schlessinger D, Keller J, Klotz E, Kelsoe G, Umezawa A, Vescovi AL, Rossant J, Kunath T, Hogan BL, Curci A, D'Urso M, Kelso J, Hide W, Ko MS: Transcriptome analysis of mouse stem cells and early embryos. PLoS Biol 2003, I(3):E74.

30. Taupin JL, Pitard V, Dechanet J, Miossec V, Gualde N, Moreau JF: Leukemia inhibitory factor: part of a large ingathering family. Int Rev Immunol I998, 16(3-4):397-426.

3I. Heinrich PC, Behrmann I, Haan S, Hermanns HM, Muller-Newen G Schaper F: Principles of interleukin (IL)-6-type cytokine signalling and its regulation. Biochem J 2003, 374(Pt I): I-20.

32. Metcalf $D$ : The unsolved enigmas of leukemia inhibitory factor. Stem Cells 2003, 2 I (I):5-I4.

33. Chambers I, Smith A: Self-renewal of teratocarcinoma and embryonic stem cells. Oncogene 2004, 23(43):7150-7I60.

34. Park JI, Strock C], Ball DW, Nelkin BD: The Ras/Raf/MEK/Extracellular Signal-Regulated Kinase Pathway Induces Autocrine-Paracrine Growth Inhibition via the Leukemia Inhibitory Factor/JAK/STAT Pathway. Mol Cell Biol 2003, 23(2):543-554

35. Chapman RS, Lourenco PC, Tonner E, Flint DJ, Selbert S, Takeda K, Akira S, Clarke AR, Watson CJ: Suppression of epithelial apoptosis and delayed mammary gland involution in mice with a conditional knockout of Stat3. Genes Dev 1999, 13(19):2604-2616.

36. Takeda K, Akira S: Multi-functional roles of Stat3 revealed by conditional gene targeting. Arch Immunol Ther Exp (Warsz) 200I, 49(4):279-283.

37. Kritikou EA, Sharkey A, Abell K, Came PJ, Anderson E, Clarkson RW, Watson CJ: A dual, non-redundant, role for LIF as a regulator of development and STAT3-mediated cell death in mammary gland. Development 2003, I30(15):3459-3468.

38. Boeuf $H$, Merienne K, Jacquot $S$, Duval $D$, Zeniou M, Hauss $C$, Reinhardt B, Huss-Garcia Y, Dierich A, Frank DA, Hanauer A, Kedinger $C$ : The ribosomal 56 kinases, cAMP-responsive elementbinding, and STAT3 proteins are regulated by different leukemia inhibitory factor signaling pathways in mouse embryonic stem cells. J Biol Chem 200I, 276(49):46204-462II.

39. Oka M, Tagoku K, Russell TL, Nakano Y, Hamazaki T, Meyer EM, Yokota T, Terada N: CD9 is associated with leukemia inhibitory factor-mediated maintenance of embryonic stem cells. Mol Biol Cell 2002, I3(4): I274-I28I.

40. Paling NR, Wheadon $\mathrm{H}$, Bone HK, Welham MJ: Regulation of embryonic stem cell self-renewal by phosphoinositide 3 kinase-dependent signaling. I Biol Chem 2004, 279(46):48063-48070

4I. Forrai A, Boyle K, Hart AH, Hartley L, Rakar S, Willson TA, Simpson KM, Roberts AW, Alexander WS, Voss AK, Robb L: Absence of suppressor of cytokine signalling 3 reduces self-renewal and promotes differentiation in murine embryonic stem cells. Stem Cells 2006, 24(3):604-6I4.

42. Nagano K, Taoka M, Yamauchi Y, Itagaki C, Shinkawa T, Nunomura K, Okamura N, Takahashi N, Izumi T, Isobe T: Large-scale identi- 
fication of proteins expressed in mouse embryonic stem cells. Proteomics 2005, 5(5):|346-|36|.

43. Watanabe S, Umehara H, Murayama K, Okabe M, Kimura T, Nakano $\mathrm{T}$ : Activation of Akt signaling is sufficient to maintain pluripotency in mouse and primate embryonic stem cells. Oncogene 2006, 25(19):2697-2707.

44. Kunath T, Saba-El-Leil MK, Almousailleakh M, Wray J, Meloche S, Smith A: FGF stimulation of the ErkI/2 signalling cascade triggers transition of pluripotent embryonic stem cells from selfrenewal to lineage commitment. Development 2007, I 34(16):2895-2902.

45. Burdon T, Stracey C, Chambers I, Nichols J, Smith A: Suppression of SHP-2 and ERK signalling promotes self-renewal of mouse embryonic stem cells. Dev Biol I 999, 2 I O(I):30-43.

46. Duval D, Malaise M, Reinhardt B, Kedinger C, Boeuf H: A p38 inhibitor allows to dissociate differentiation and apoptotic processes triggered upon LIF withdrawal in mouse embryonic stem cells. Cell Death Differ 2004, I I(3):33I-34I.

47. Sekkai D, Gruel G, Herry M, Moucadel V, Constantinescu SN, Albagli O, Tronik-Le Roux D, Vainchenker W, Bennaceur-Griscelli A: Microarray analysis of LIF/Stat3 transcriptional targets in embryonic stem cells. Stem Cells 2005, 23(I0): I 634-1642.

48. Duval D, Reinhardt B, Kedinger C, Boeuf H: Role of suppressors of cytokine signaling (Socs) in leukemia inhibitory factor (LIF) dependent embryonic stem cell survival. Faseb J 2000 I 4(I I): I577-I 584 .

49. Irizarry RA, Bolstad BM, Collin F, Cope LM, Hobbs B, Speed TP: Summaries of Affymetrix GeneChip probe level data. Nucleic Acids Res 2003, 3 I(4): el5.

50. Benjamini YaH Y: Controlling the false discovery rates: A practical and powerful approach to multipl testing. I $R$ Statist Soc 1995, B57:289-300.

5I. Pawitan Y, Michiels S, Koscielny S, Gusnanto A, Ploner A: False discovery rate, sensitivity and sample size for microarray studies. Bioinformatics 2005, 2 I (I 3):3017-3024.

52. Eisen MB, Spellman PT, Brown PO, Botstein D: Cluster analysis and display of genome-wide expression patterns. Proc Natl Acad Sci USA 1998, 95(25): I 4863-14868.

53. Chambers I, Silva J, Colby D, Nichols J, Nijmeijer B, Robertson M, Vrana J, Jones K, Grotewold L, Smith A: Nanog safeguards pluripotency and mediates germline development. Nature 2007, 450(7 I73): I230-1234.

54. Carter MG, Stagg CA, Falco G, Yoshikawa T, Bassey UC, Aiba K, Sharova LV, Shaik N, Ko MS: An in situ hybridization-based screen for heterogeneously expressed genes in mouse ES cells. Gene Expr Patterns 2008, 8(3): $181-198$.

55. Chen $X, X u H$, Yuan $P$, Fang $F$, Huss $M$, Vega VB, Wong E, Orlov $Y L$ Zhang W, jiang J, Loh YH, Yeo HC, Yeo ZX, Narang V, Govindarajan KR, Leong B, Shahab A, Ruan Y, Bourque G, Sung WK, Clarke ND, Wei $\mathrm{CL}, \mathrm{Ng} \mathrm{HH}$ : Integration of external signaling pathways with the core transcriptional network in embryonic stem cells. Cell 2008, 133(6): I I06-III 17.

56. Zhang $X$, Zhang J, Wang T, Esteban MA, Pei D: ESRRB activates Oct4 transcription and sustains self renewal and pluripotency in embryonic stem cells. J Biol Chem 2008 283(5 I):35825-35833.

57. Kittler R, Putz G, Pelletier L, Poser I, Heninger AK, Drechsel D, Fischer S, Konstantinova I, Habermann B, Grabner H, Yaspo ML, Himmelbauer H, Korn B, Neugebauer K, Pisabarro MT, Buchholz F: An endoribonuclease-prepared siRNA screen in human cells identifies genes essential for cell division. Nature 2004 432(7020): $1036-1040$.

58. Hailesellasse Sene K, Porter CJ, Palidwor G, Perez-Iratxeta C, Muro EM, Campbell PA, Rudnicki MA, Andrade-Navarro MA: Gene function in early mouse embryonic stem cell differentiation. $B M C$ Genomics 2007, 8:85.

59. Duval D, Trouillas M, Thibault $C$, Dembele $D$, Diemunsch F, Reinhardt B, Mertz AL, Dierich A, Boeuf H: Apoptosis and differentiation commitment: novel insights revealed by gene profiling studies in mouse embryonic stem cells. Cell Death Differ 2006 , 13(4):564-575.

60. Takahashi Y, Takahashi M, Carpino N, Jou ST, Chao JR, Tanaka S, Shigeyoshi Y, Parganas E, Ihle JN: Leukemia inhibitory factor regulates trophoblast giant cell differentiation via Janus kinase I-signal transducer and activator of transcription 3-suppres- sor of cytokine signaling 3 pathway. Mol Endocrinol 2008, 22(7):1673-168|.

61. Lord KA, Abdollahi A, Thomas SM, DeMarco M, Brugge JS, HoffmanLiebermann $B$, Liebermann DA: Leukemia inhibitory factor and interleukin-6 trigger the same immediate early response, including tyrosine phosphorylation, upon induction of myeloid leukemia differentiation. Mol Cell Biol |99|, I I (9):437I-4379.

62. Nguyen HQ, Hoffman-Liebermann B, Liebermann DA: The zinc finger transcription factor Egr- $I$ is essential for and restricts differentiation along the macrophage lineage. Cell 1993, 72(2): 197-209.

63. Liebermann DA, Hoffman B: MyD genes in negative growth control. Oncogene 1998, 17(25):3319-3329.

64. Florholmen G, Andersson KB, Yndestad A, Austbo B, Henriksen UL, Christensen $G$ : Leukaemia inhibitory factor alters expression of genes involved in rat cardiomyocyte energy metabolism. Acta Physiol Scand 2004, I 80(2): I33-142.

65. Wright LS, Li J, Caldwell MA, Wallace K, Johnson JA, Svendsen CN: Gene expression in human neural stem cells: effects of leukemia inhibitory factor. J Neurochem 2003, 86(I): 179-195.

66. Sherwin JR, Freeman TC, Stephens RJ, Kimber S, Smith AG, Chambers I, Smith SK, Sharkey AM: Identification of genes regulated by leukemia-inhibitory factor in the mouse uterus at the time of implantation. Mol Endocrinol 2004, I 8(9):2 I 85-2 I 95.

67. Minami M, Inoue M, Wei S, Takeda K, Matsumoto M, Kishimoto T, Akira S: STAT3 activation is a critical step in gp I 30 -mediated terminal differentiation and growth arrest of a myeloid cell line. Proc Natl Acad Sci USA 1996, 93:3963-3966.

68. Hirano T, Nakajima K, Hibi M: Signaling mechanisms through gp 130: a model of the cytokine system. Cytokine Growth Factor Rev 1997, 8:24I-252.

69. Cinelli P, Casanova EA, Uhlig S, Lochmatter P, Matsuda T, Yokota T, Rulicke $T$, Ledermann B, Burki K: Expression profiling in transgenic FVB/N embryonic stem cells overexpressing STAT3. BMC Dev Biol 2008, 8:57.

70. Worthington MT, Pelo JW, Sachedina MA, Applegate JL, Arseneau KO, Pizarro TT: RNA binding properties of the AU-rich element-binding recombinant Nup475/TISI I/tristetraprolin protein. J Biol Chem 2002, 277(50):48558-48564.

7I. Murata T, Morita N, Hikita K, Kiuchi K, Kaneda N: Recruitment of mRNA-destabilizing protein TISII to stress granules is mediated by its zinc finger domain. Exp Cell Res 2005, 303(2):287-299.

72. Lai WS, Parker JS, Grissom SF, Stumpo DJ, Blackshear PJ: Novel mRNA targets for tristetraprolin (TTP) identified by global analysis of stabilized transcripts in TTP-deficient fibroblasts. Mol Cell Biol 2006, 26(24):9196-9208.

73. Orkin $\mathrm{SH}$ : Chipping away at the embryonic stem cell network. Cell 2005, I 22(6):828-830.

74. Burdon T, Chambers I, Stracey C, Niwa H, Smith A: Signaling mechanisms regulating self-renewal and differentiation of pluripotent embryonic stem cells. Cells Tissues Organs 1999, 165(3-4): | $3|-| 43$.

75. Aksoy I, Sakabedoyan C, Bourillot PY, Malashicheva AB, Mancip J, Knoblauch K, Afanassieff M, Savatier P: Self-renewal of murine embryonic stem cells is supported by the serine/threonine kinases Pim-I and Pim-3. Stem Cells 2007, 25(I 2):2996-3004.

76. Sharova LV, Sharov AA, Piao Y, Shaik N, Sullivan T, Stewart CL, Hogan BL, Ko MS: Global gene expression profiling reveals similarities and differences among mouse pluripotent stem cells of different origins and strains. Dev Biol 2007, 307(2):446-459.

77. Loh YH, Zhang W, Chen X, George J, Ng HH: Jmjd I a and Jmjd2c histone $\mathrm{H} 3$ Lys 9 demethylases regulate self-renewal in embryonic stem cells. Genes Dev 2007, 2 I (20):2545-2557.

78. Meshorer E, Misteli T: Chromatin in pluripotent embryonic stem cells and differentiation. Nat Rev Mol Cell Biol 2006, 7(7):540-546

79. Toyooka Y, Shimosato D, Murakami K, Takahashi K, Niwa H: Identification and characterization of subpopulations in undifferentiated ES cell culture. Development 2008, 135(5):909-918.

80. Frank DA: STAT signaling in the pathogenesis and treatment of cancer. Mol Med 1999, 5(7):432-456.

8I. Doss MX, Winkler J, Chen S, Hippler-Altenburg R, Sotiriadou I, Halbach M, Pfannkuche K, Liang $\mathrm{H}$, Schulz $\mathrm{H}$, Hummel $\mathrm{O}$, Hubner $\mathrm{N}$, Rottscheidt R, Hescheler J, Sachinidis A: Global transcriptome 
analysis of murine embryonic stem cell-derived cardiomyocytes. Genome Biol 2007, 8(4):R56.

82. Verhaak RG, Sanders MA, Bijl MA, Delwel R, Horsman S, Moorhouse MJ, Spek PJ van der, Lowenberg B, Valk PJ: HeatMapper: powerful combined visualization of gene expression profile correlations, genotypes, phenotypes and sample characteristics. BMC Bioinformatics 2006, 7:337.

83. Trouillas M, Saucourt C, Duval D, Gauthereau X, Thibault C, Dembele D, Feraud O, Menager J, Rallu M, Pradier L, Boeuf H: Bcl2, a transcriptional target of p38alpha, is critical for neuronal commitment of mouse embryonic stem cells. Cell Death Differ 2008, I 5(9): I 450- I 459.

84. Henschel A, Buchholz F, Habermann B: DEQOR: a web-based tool for the design and quality control of siRNAs. Nucleic Acids Res 2004:WII3-I20.

Publish with Bio Med Central and every scientist can read your work free of charge

"BioMed Central will be the most significant development for disseminating the results of biomedical research in our lifetime. "

Sir Paul Nurse, Cancer Research UK

Your research papers will be:

- available free of charge to the entire biomedical community

- peer reviewed and published immediately upon acceptance

- cited in PubMed and archived on PubMed Central

- yours - you keep the copyright

Submit your manuscript here:

http://www.biomedcentral.com/info/publishing_adv.asp
BioMedcentral 